\title{
Soil Hydraulic Properties of Plinthosol in the Middle Yangtze River Basin, Southern China
}

\author{
Yongwu Wang ${ }^{1}$, Tieniu $\mathrm{Wu}^{1,2, * \mathbb{D}}$, Jianwu Huang ${ }^{1}$, Pei Tian ${ }^{1, *} \mathbb{0}$, Hailin Zhang ${ }^{1}$ and \\ Tiantian Yang ${ }^{3}$ (i) \\ 1 Key Laboratory for Geographical Process Analysis \& Simulation, Central China Normal University, \\ Wuhan 430079, China; wangyw@mails.ccnu.edu.cn (Y.W.); wgjzhjw@mail.ccnu.edu.cn (J.H.); \\ hailzhang@mail.ccnu.edu.cn (H.Z.) \\ 2 Department of Ecosystem Science and Management, The Pennsylvania State University, University Park, \\ PA 16802, USA \\ 3 School of Civil Engineering and Environmental Science, The University of Oklahoma, Norman, OK 73019, \\ USA; Tiantian.Yang@ou.edu \\ * Correspondence: wutieniu01@mail.ccnu.edu.cn (T.W.); tianpei@mail.bnu.edu.cn (P.T.)
}

Received: 16 May 2020; Accepted: 20 June 2020; Published: 23 June 2020

\begin{abstract}
Soil hydraulic properties are ecologically important in arranging vegetation types at various spatial and temporal scales. However, there is still a lack of detailed understanding of the basic parameters of plinthosol in the Middle Yangtze River basin. This paper focuses on the soil hydraulic properties of three plinthosol profiles at Yueyang (YE), Wuhan (WH), and Jiujiang (JU) and tries to reveal the origin of plinthosol and the relationship among the soil hydraulic parameters. Discriminant analysis indicated that the plinthosol in the JU profile was of aeolian origin, while that in the $\mathrm{WH}$ and YE profiles was of alluvial origin; soil hydraulic properties varied greatly among these profiles. The proportion of macro-aggregates $(>0.25 \mathrm{~mm}$, weight $\%)$ in the JU profile $(88.28 \%)$ was significantly higher than that in the WH (73.63\%) and YE (57.77\%) profiles; the water holding capacity and saturated hydraulic conductivity of JU plinthosol was also higher than that of WH and YE plinthosol; the fact that $D_{r}$ and $D_{i}$ of the JU profile are lower than those of the $\mathrm{YE}$ and $\mathrm{WH}$ profiles illustrates the stability of JU plinthosol is better than that of YE and WH plinthosol, which is consistent with the fractal dimension of aggregates. The disintegration curves of white vein and red matrix demonstrated a large discrepancy in the JU profile, but these curves showed a similar trend in the WH and YE profiles. The differences in hydraulic properties might be ascribed to the origin of plinthosol, and the results of the fractal dimension also confirmed this conclusion. This study might provide a better understanding of the soil physical properties of plinthosol and shed light on the soil and water conservation measures in the Middle Yangtze River basin.
\end{abstract}

Keywords: plinthosol; soil hydraulic properties; discriminant analysis; fractal dimension; Middle Yangtze River

\section{Introduction}

Soil hydraulic properties are important for plant growth, soil and water conservation, and tillage operations [1]. It includes, but not limited to saturated hydraulic conductivity $\left(K_{s}\right)$, water-stable aggregate (WSA), soil water retention curve (SWRC), and disintegration rate $\left(D_{r}\right)[2,3]$. The soil hydraulic properties are crucial parameters for ecological construction and farmland management.

In the Middle Yangtze River basin, many environmental problems are challenging the carrying capacity of the natural ecosystems, such as soil erosion, land degradation, and soil pollution [4]. These problems are directly or indirectly related to the soil properties and soil quality. The zonal soil 
type in the study area is ultisol in the Soil Taxonomy System of the USA [5], and one of the widespread soil types on the plain and gentle hills is plinthosol [6,7]. It occupies approximately $1.28 \times 10^{6} \mathrm{~km}^{2}$ in Southern China [8]. Plinthosol, also named Quaternary red clay, or vermiculated red clay or reticulated red clay, which was defined as an iron-rich, humus-poor mixture of clay with quartz and other diluents which commonly occurred as dark red redox mottles [9]. Plinthosol could be divided into two parts: red matrix and white vein. The color of the red matrix was similar to southern red clay; but the color of white vein varied greatly from one site to another: some were pure white; some were pale yellow or light gray. The morphology of the white vein was worm-like, dendritic, spotted, or net-like vine [10]. Previous studies showed that the special feature of plinthosol was the product of the paleo-environment, and it conserved abundant information of environmental evolution $[8,11]$. Hence, the variations in color and morphology might indicate different parent materials or pedogenic processes. In order to find out the origin of plinthosol, a number of studies on the origin and soil formation process of plinthosol were conducted [8,10-15]. The particle size characteristics, mineralogical composition, and rare earth element patterns indicated that the plinthosol had multiple origins, and one of the main origins was aeolian sediment $[6,13,16]$. During the process of aeolian dust deposition, or at the end of each deposition stage, the groundwater table fluctuated in response to dry and rainy seasons. Clay minerals migrated, quartz had been amassed in the white vein, and iron oxide depletion occurred in the red matrix, which increased the size of the white vein, and resulted in the mosaic structure of reticulate red clay and worm-like white veins $[10,14,17]$. This process has greatly altered the physical and chemical properties of the aeolian sediment, especially the soil micro-structure and the particle composition, which affected the soil hydraulic properties, such as saturated water conductivity $\left(K_{S}\right)$, water-stable aggregates (WSA) content, and disintegration rate $\left(D_{r}\right)$.

The study of soil hydraulic properties is of great importance for the understanding of the mechanism, process, and prevention of soil erosion [18]. For example, soil disintegration rate and aggregate stability were directly related to the soil erodibility; hence, these parameters were applied in the Revised Universal Soil Loss Equation (RUSLE) and Watershed Erosion Prediction Project (WEPP) [19,20], and these models were widely used in the prediction of soil erosion. In the Middle Yangtze River basin, soil erosion is an important and unresolved issue, and it is of great significance to obtain the basic hydraulic parameters of the plinthosol for modelling the soil erosion process. Besides, some parameters, such as saturated water conductivity, initial water content, and soil particle composition strongly affect the soil infiltration rate and characteristics and surface and underground runoff, which not only influence the erosion process, but also the vegetation growth, vegetation type, and its effect on the soil and water conservation [21,22]. During the process of vegetation reconstruction, soil moisture in the root zone is responsive to rainfall and infiltration and will induce substantial change of the SWRC [2,18,23-30]. Hence, the interrelations between soil moisture, soil hydraulic properties, and soil erosion are crucial for the maintenance of ecological health.

For the plinthosol of the Middle Yangtze River basin, most of the previous studies focused on its origin, paleo-environmental significance, soil mechanical properties, or erosion process. As one of the basic and valuable characteristics in soil studies, the hydraulic properties of plinthosols are hitherto given inadequate attention. Therefore, three typical profiles in the Middle Yangtze River basin were chosen to study the soil hydraulic properties of saturated water conductivity, water retention characteristic curves, disintegration characteristics, and water-stable aggregates. Meanwhile, in order to explore the differences in physicochemical mechanisms of soil hydraulic characteristics in different areas, the parameters of soil particle size composition and organic matter content were also tested. The main purpose of this study was to reveal the trend of water holding capacity in the profile and explore the relationship between SWRC, WSA, $D_{r}, K_{s}$, and particle size of plinthosol and determine the difference of red matrix and white veins of plinthosol. Finally, these findings may provide a scientific basis for the ecological construction and soil erosion control in South China. 


\section{Materials and Methods}

\subsection{Study Sites}

Three typical profiles were selected to carry out this study (Figure 1). The Yueyang (YE) profile is located near the crossroads of Huangshawan Road and Xuefu Road $\left(29^{\circ} 19^{\prime} 48^{\prime \prime}\right.$ N, $113^{\circ} 4^{\prime} 25^{\prime \prime}$ E). The profile is about $2.5 \mathrm{~m}$ thick. The topsoil vegetation was dominated by Poa annua L. Most of the root system resides in the surface soil $(20 \mathrm{~cm})$. The color of the red matrix was $2.4 \mathrm{YR} 3 / 6$ and that of the white vein was 5 Y 8/1; the white veins and red matrix were irregularly distributed in the profile (Figure 2A). The Jiujiang (JU) profile is located at Jiulongshan Park near Xingcheng Avenue $\left(29^{\circ} 39^{\prime} 39^{\prime \prime} \mathrm{N}, 115^{\circ} 57^{\prime} 13^{\prime \prime} \mathrm{E}\right)$. The profile was about $1.5 \mathrm{~m}$ thick. The color of the red matrix was $2.5 \mathrm{YR}$ $4 / 5$ and that of the white vein was 5 Y 7/3; the white vein exhibited a more yellowish hue as compared with that in the YE profile. The JU profile could be divided into three sub-layers: the surface layer $(0-30 \mathrm{~cm})$ was dominated by red clay; the middle layer $(30-60 \mathrm{~cm})$ was a typical reticulate layer; and the bottom layer $(60-100 \mathrm{~cm})$ was a weak reticulate layer, which could be classified as a poorly developed layer (Figure 2B). The Wuhan (WH) profile is located at the center of Wuhan East Lake Comprehension Free Trade Zone $\left(30^{\circ} 26^{\prime} 26^{\prime \prime} \mathrm{N}, 114^{\circ} 28^{\prime} 56^{\prime \prime} \mathrm{E}\right)$. The color of the red matrix was $2.5 \mathrm{YR} 5 / 8$ and that of the white vein was 5 Y 8/1. The profile could also be divided into three sub-layers: The topsoil $(10-20 \mathrm{~cm})$ was an abandoned layer; the middle layer $(20-50 \mathrm{~cm})$ was an illuvial horizon which contained more iron-manganese concretion; and the bottom layer $(50-100 \mathrm{~cm})$ was a strong reticulated layer which contained more typical white vein (Figure 2C).

The red and brown color of plinthosol was caused by Fe oxide. Generally, the red matrix contains more Fe oxide and leads to brown color; the white vines contain less Fe oxide and show white and light-yellow color. Clay minerals are fairly stable and are an important component of soil, and clay minerals in the plinthosol are mainly illite, kaolinite, illite-smectite mixed-layer clays, and minor chlorite [10]. Mineral types in different places are slightly different, which is caused by differences of weathering and origin [15].

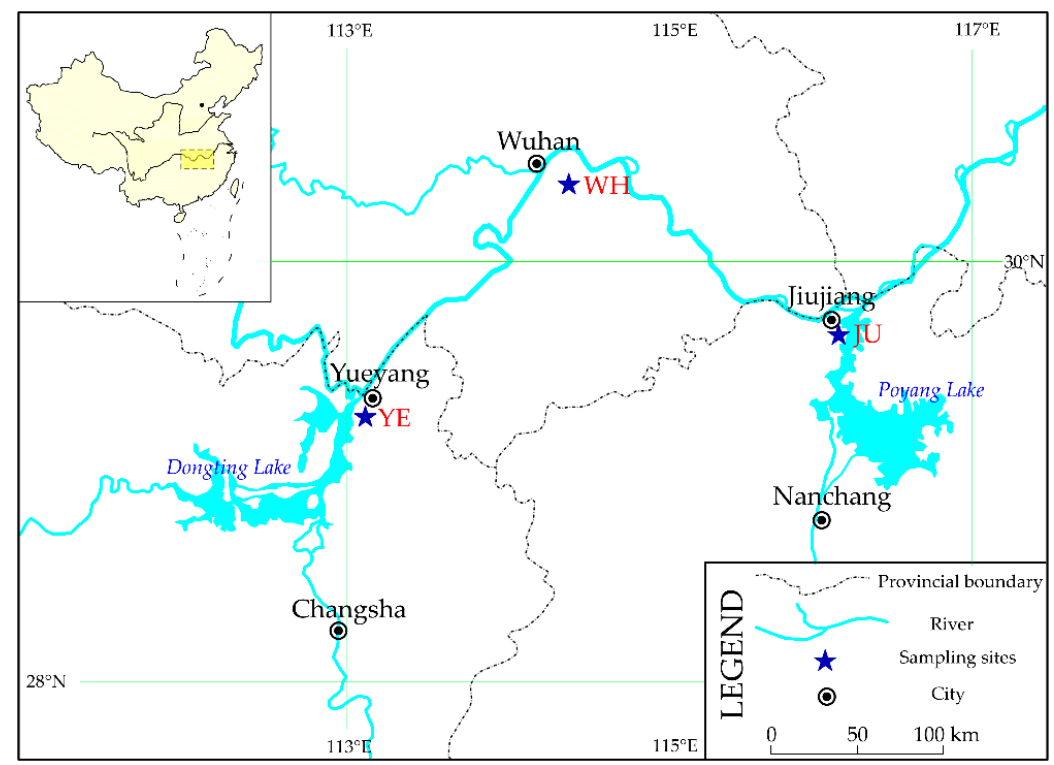

Figure 1. Schematic map showing the locations of plinthosol profiles in Jiujiang (JU), Wuhan (WH), and Yueyang (YE). 


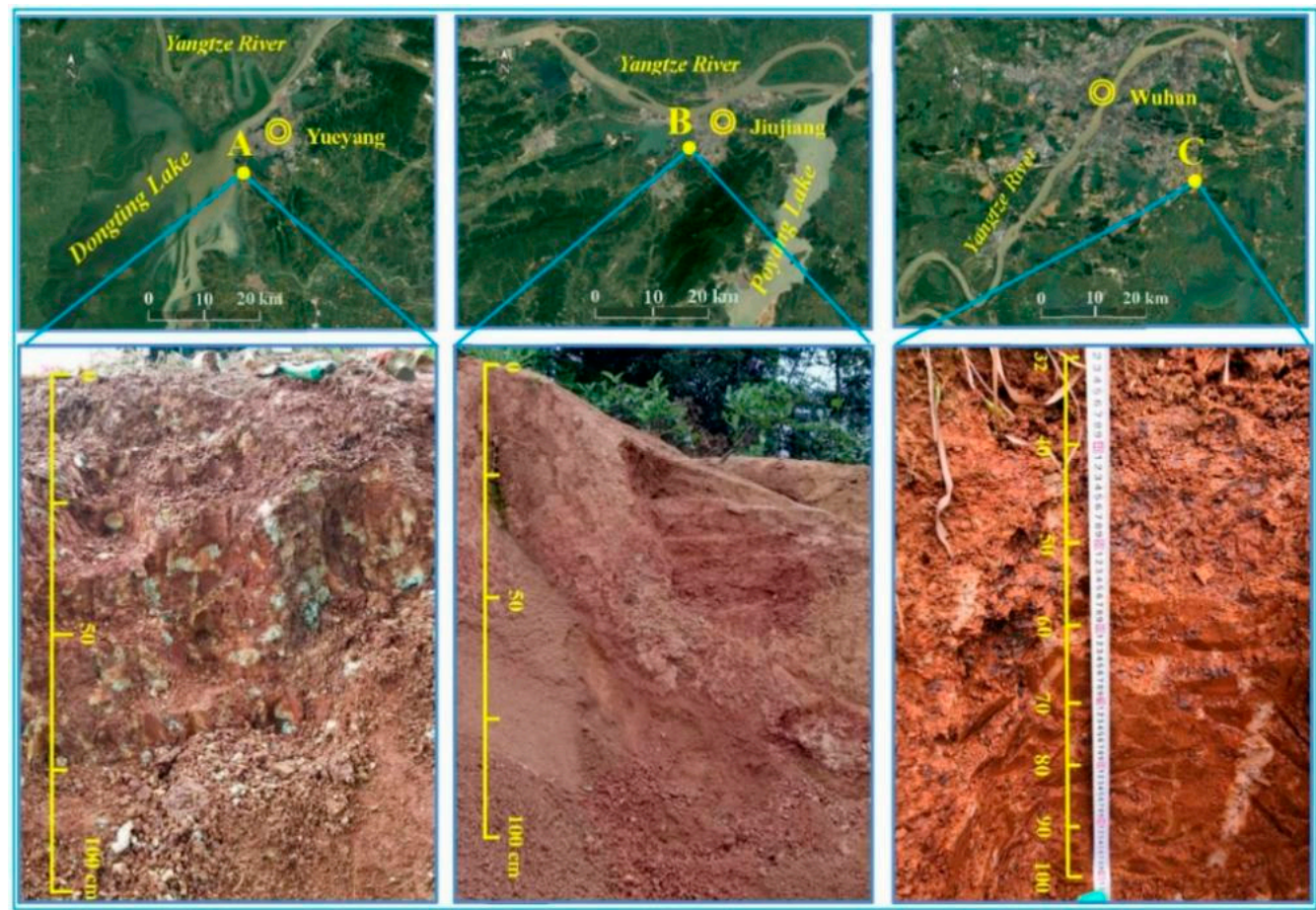

Figure 2. The locations of the sampled profiles of Yueyang (YE), Jiujiang (JU), and Wuhan (WH). (The A, $\mathbf{B}$ and $\mathbf{C}$ represent the location of $\mathrm{YE}, \mathrm{JU}$ and $\mathrm{WH}$ profile, respectively.).

All three study sites are located in the middle reaches of the Yangtze River, where a subtropical monsoon climate is the main climate type. In Jiujiang City, the annual average temperature is $16{ }^{\circ} \mathrm{C}$ to $17^{\circ} \mathrm{C}$; the annual rainfall is $1300 \mathrm{~mm}$ to $1600 \mathrm{~mm}$, and more than $40 \%$ is concentrated in the second quarter. Heavy rains are relatively frequent during the rainy season. In Wuhan City, the annual average temperature is $15.8{ }^{\circ} \mathrm{C}$ to $17.5^{\circ} \mathrm{C}$, the annual precipitation is $1150 \mathrm{~mm}$ to $1450 \mathrm{~mm}$. The rainfall is concentrated in June to August every year. The precipitation of these three months accounts for $40 \%$ of the annual rainfall. In Yueyang City, the annual average temperature is $16.5^{\circ} \mathrm{C}$ to $17.2^{\circ} \mathrm{C}$. The annual rainfall is $1290 \mathrm{~mm}$ to $1560 \mathrm{~mm}$, and 70\% of the precipitation is concentrated in the spring and summer; the annual distribution of rainfall is uneven at the YE site.

\subsection{Soil Sampling}

The sampling depth depends on the maximum rooting depth and rill depth. In the study sites, the root systems of herbs and shrubs were limited to the depth of $100 \mathrm{~cm}$, as well as rill erosion [31]. Therefore, the sampling depth should be no more than one meter, where the roots developed and organic matter accumulated $[23,24,26]$.

Sampling was conducted from March to October, 2018. The weathered or contaminated soil layer was removed in advance. The sampling interval was $10 \mathrm{~cm}$. In the JU and $\mathrm{WH}$ profiles, 10 groups of samples were obtained vertically, and the total sampling depth was $100 \mathrm{~cm}$. In the YE profile, the plants had shallower root systems; only nine groups of samples were collected, and the sampling depth was $90 \mathrm{~cm}$. Besides, white vein and red matrix were collected separately for each profile.

Undisturbed soil samples were collected by cutting rings $\left(100 \mathrm{~cm}^{3}\right)$, and bulk soil samples were collected by zip-lock bags. All the samples were air-dried for about one week. Large bulk samples were taken to test the water stable aggregates and disintegration behavior. All the test items were averaged over three repetitions. These experiments were conducted in the key laboratory for geographical process analysis and simulation, Hubei Province, Central China Normal University (Wuhan, China). 


\subsection{Measurements of the Hydraulic Parameters}

Particle size distribution was measured using the Mastersizer 3000 laser particle size analyzer (Malvern Instruments Ltd., Malvern, UK). The main pretreatment processes were as follows: firstly, $10 \%$ hydrogen peroxide $\left(\mathrm{H}_{2} \mathrm{O}_{2}\right)$ was added to remove soil organic matter. Then hydrochloric acid $(\mathrm{HCl})$ was added to remove carbonates. All soil samples received ultrasonic treatment for 10 min before laser diffraction measurement. The U.S. Soil Taxonomy system [32] was used to classify the soil texture and the median diameter (MD); the percentages of clay $(<2 \mu \mathrm{m})$, silt $(2-50 \mu \mathrm{m})$, and sand $(>50 \mu \mathrm{m})$ were calculated.

Soil saturated hydraulic conductivity $\left(K_{S}\right)$ was measured on undisturbed soil cores using the constant-head permeameter. Each layer was characterized by averaging three measurements of $K_{s}$ value $[28,33,34]$. The saturated hydraulic conductivity was calculated by Formula (1):

$$
K_{t}=\frac{Q \times L}{t \times s \times \Delta h}
$$

where $K_{t}$ is saturation conductivity at the temperature $t^{\circ} \mathrm{C}(\mathrm{cm} / \mathrm{h}) ; Q$ is the $N$-th amount of seepage water $(\mathrm{mL}) ; t$ is the time interval $(\mathrm{h}) ; s$ is the cross-sectional area of infiltration $\left(\mathrm{cm}^{2}\right) ; L$ is the height of cutting ring samples $(\mathrm{cm}) ; \Delta h$ is the inflow and outflow difference $(\mathrm{cm})$.

During the measuring process, the temperature is not exactly constant. To ensure the comparability of the tested data, all the data should be converted to the saturated hydraulic conductivity at $10{ }^{\circ} \mathrm{C}$ by Formula (2):

$$
K_{10}=\frac{K_{t}}{0.7+0.03 t}
$$

where the $t$ is the measured temperature in the laboratory when the experiment was conducted $\left({ }^{\circ} \mathrm{C}\right)$.

Soil water-stable aggregates were measured using the wet sieving method (the type of device was TTF-100, produced by Shangyu Shunlong Laboratory Instruments Factory, Zhejiang Province, China) [35]. After putting the soil samples onto the top sieve, the set of sieves was immersed in water and shaken vertically 30 times per minute at $4 \mathrm{~cm}$ amplitude for $30 \mathrm{~min}$. The aggregates retained on each sieve were collected and weighed after drying at $105{ }^{\circ} \mathrm{C}$ to dry completely $(24 \mathrm{~h})$. The mesh sizes for sieves were $5 \mathrm{~mm}, 2 \mathrm{~mm}, 1 \mathrm{~mm}, 0.5 \mathrm{~mm}$, and $0.25 \mathrm{~mm}$, respectively. The results were expressed as the proportion of water stable aggregates $>0.25 \mathrm{~mm}$ diameter (which was also named soil macro-aggregates). All samples were averaged over two repetitions. In this study, the mean weight diameter $(M W D)$ and geometric mean diameter $(G M D)$ were calculated to determine the stability of aggregates [36]. Furthermore, the fractal dimension based on the soil aggregates was calculated [37,38]. The parameters were obtained according to Formulas (3) to (5):

$$
\begin{gathered}
M W D=\sum_{i=1}^{n} x_{i} y_{i} \\
G M D=\exp \left\{\frac{\sum_{i=1}^{n} w_{i} \ln x_{i}}{\sum_{i=1}^{n} w_{i}}\right\} \\
\left(\frac{d_{i}}{d_{\max }}\right)^{3-D}=\frac{m_{i}}{m_{\max }}
\end{gathered}
$$

where $y_{i}$ is the proportion of each size class with respect to the total sample and $x_{i}$ the mean diameter of the size class $(\mathrm{mm}) . w_{i}$ is the weight of the soil aggregates of each size class $(\mathrm{g}) . d_{i}$ is the aggregates size class; $d_{\text {max }}$ is the mean diameter of the largest aggregates class; $D$ is the fractal dimension; $m_{i}$ is cumulative mass of aggregates of a size less than the $i$-th size fraction, and $m_{\max }$ is the total mass of all size fraction aggregates.

The measurement of the disintegration rate was conducted by a self-made instrument (Figure 3). The instrument was composed of an electronic balance and mesh sieve $(1 \mathrm{~cm} \times 1 \mathrm{~cm})$ below. The whole 
process of the disintegration experiment was recorded by a camera, and the data were extracted from the video. The disintegration index $\left(D_{i}\right)$ and disintegration rate $\left(D_{r}\right)$ were calculated by Formulas (6) and (7):

$$
\begin{aligned}
& D_{i}=\frac{M_{t}}{M} \times 100 \% \\
& D_{r}=\frac{D_{i}}{t} \times 100 \%
\end{aligned}
$$

where the $M_{t}$ is the total disintegration weight after $t$ seconds (g); $M$ is the weight of the soil sample (g). In this study, in view of all the soil samples not having continued to disintegrate after $6 \mathrm{~min}, 6 \mathrm{~min}$ was used as the most appropriate $t$ value in Formula (7) to calculate the mean $D_{r}$ value of plinthosol.

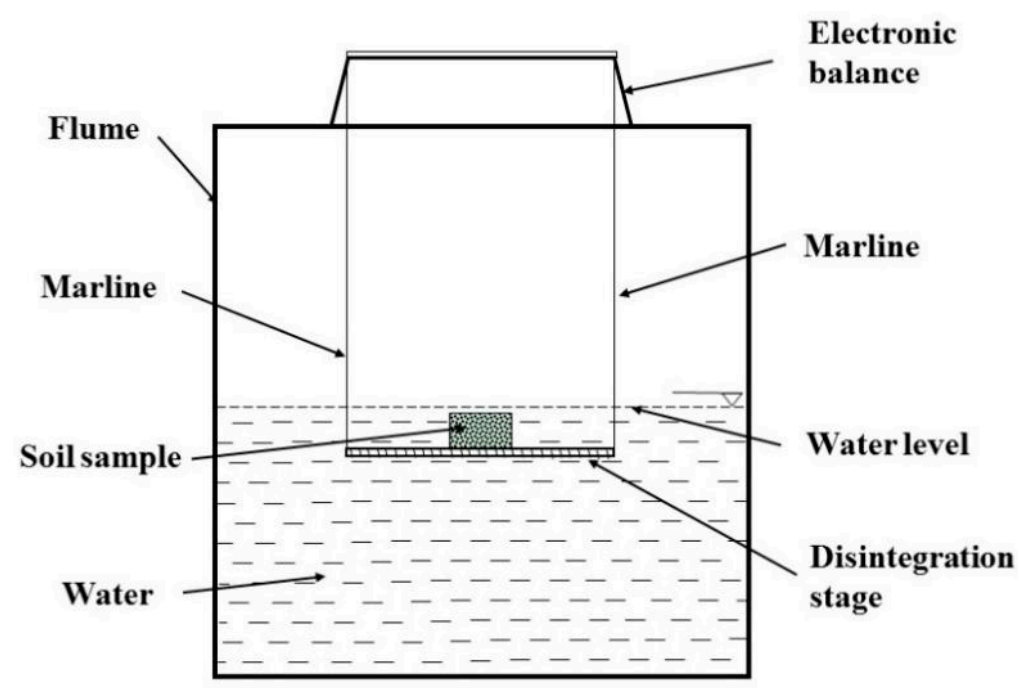

Figure 3. Schematic diagram of soil disintegration equipment.

Water retention curves were determined by using plate extractors (Soil Moisture Equipment Corp., Santa Barbara, CA, USA). Keeping the indoor temperature at $25^{\circ} \mathrm{C}$ steadily during the whole experimental process, soil-water retention at 10, 20, 40, 60, 80, 100, 300, 500, 800, and $1000 \mathrm{kPa}$ was tested by using the plate extractors. After the determination of the soil water retention curve, all soil cores were weighed and oven-dried at $105^{\circ} \mathrm{C}$ to constant weight to determine the bulk density by the core method [39]. The soil water retention curve model (RETC, version 6.02) [40] was used for fitting the soil water retention data. The maximum number of iterations was set to 50. The type of the retention curve model was van Genuchten, $m=1-1 / n$ (type 3 ). The equation used for the fitting by RETC is Formula (8):

$$
\frac{\theta-\theta_{r}}{\theta_{s}-\theta_{r}}=\frac{1}{\left[1+(\alpha h)^{n}\right]^{m}}
$$

where $\theta$ is the water content $\left(\mathrm{cm}^{3} \cdot \mathrm{cm}^{-3}\right) ; \theta_{r}$ is the residual water content; $\theta_{S}$ is the saturated water content; $h$ is the matric potential $(\mathrm{kPa})$; and $\alpha\left(\mathrm{kPa}^{-1}\right), n$, and $m(m=1-1 / n)$ are empirical parameters [41].

\subsection{Discriminant Analysis}

Discriminant analysis is a multivariate statistical analysis method to discriminate the origin of modern alluvial, diluvial, or aeolian deposition and to confirm the depositional environments by sedimentary or geochemical characteristics [42]. The basic theory of this method is to make the samples with the same properties gather as much as possible and samples with different properties as far away as possible through calculation. One of the classical statistical classification methods is linear discriminant analysis (LDA), which was proposed by Fisher in 1938. Previous studies showed that discriminant parameters could be divided into two types: (1) geochemical element parameters, mainly 
the characteristics of rare earth element (REE) content [43], and (2) soil particle parameters, mainly the mean particle size, standard deviation, skewness, and kurtosis [44,45].

In this study, soil particle size composition was adopted as the basic data to find out whether the plinthosol of the three profiles could fall into the same category. Four parameters, mean particle size, standard deviation, skewness, and kurtosis, were chosen to characterize the sedimentary feature. The mean particle size represents the average degree of the soil particle diameter and reflects the energy of the transportation medium. The standard deviation represents the dispersion degree of soil particles and reflects the uniformity of the sediment. The skewness represents the symmetry of the soil particle distribution and reflects relative content of coarse and fine particles of soil particle. The kurtosis represents the sharpness of the soil particle size frequency curve and reflects the convex and dispersion degree of the particle size distribution curve [45]. All four parameters were calculated by Formulas (9) to (12). The sample discriminant value $(Y)$ was calculated by Formula (13):

$$
\begin{gathered}
M_{Z}=\frac{1}{100} \sum_{i=1}^{n} f_{i} X_{i} \\
\sigma_{I}^{2}=\sqrt{\frac{1}{100} \sum_{i=1}^{n}\left(X_{i}-X\right)^{2} f_{i}} \\
K_{Z}=\sigma^{-3} \frac{1}{100} \sum_{i=1}^{n}\left(X_{i}-X\right)^{3} f_{i} \\
K_{G}=\sigma^{-4} \frac{1}{100} \sum_{i=1}^{n}\left(X_{i}-X\right)^{4} f_{i} \\
Y=-3.5688 M_{Z}+3.7016 \sigma_{I}^{2}-2.0766 K_{Z}+3.1135 K_{G}
\end{gathered}
$$

where $X_{i}$ is the midpoint particle diameter of the $i$-th size fraction (the median value of the maximum and minimum of the $i$-th size fraction, such that the midpoint particle diameter of $0-2 \mu \mathrm{m}$ is $1 \mu \mathrm{m}), f_{i}$ is the percent content of $i$-th size fraction; $M_{Z}, \sigma_{I}^{2}, K_{Z}$, and $K_{G}$ are mean particle size, standard deviation, skewness, and kurtosis, respectively; $Y$ is the discriminant parameter, which was initially calculated by Sahu in 1964 [41], and different samples had a relatively wide variation scale [46]. Many discriminant functions were established to discriminate the origins of soil samples [42-46]; among them, the model proposed by Sahu (Formula (13)) was frequently employed in calculating the discriminant parameter of fluvial and lacustrine samples, and the results were all negative. The employed discriminant value $(Y=-2.7411)$ was obtained by analyzing a large number of soil samples, which was based on the fact that the soil particle size distribution was a documentation of the depositional environment.

\section{Results}

\subsection{Basic Physical and Chemical Properties}

Some basic properties are shown in Table 1. The bulk density (BD) of WH plinthosol was the highest $\left(1.56 \mathrm{~g} \cdot \mathrm{cm}^{-3}\right.$ on average), and that of the YE profile was the lowest $\left(1.37 \mathrm{~g} \cdot \mathrm{cm}^{-3}\right.$ on average); $\mathrm{JU}$ plinthosol contained the highest organic matter $\left(4.67 \mathrm{~g} \cdot \mathrm{kg}^{-1}\right.$ on average), and that of YE plinthosol was the lowest ( $3.02 \mathrm{~g} \cdot \mathrm{kg}^{-1}$ on average).

As Figure 4 shows, the curves of particle-size distribution (PSD) show a decreasing trend in all the profiles. The clay content was lower and silt content was higher at the surface, while the converse was found at the bottom of each profile. However, some specific differences between these profiles could be detected by examining the data. For example, the clay fraction $(0-2 \mu \mathrm{m})$ in the YE profile was $43.22 \%$, which was higher than the $35.42 \%$ in the JU profile and $36.22 \%$ in the $\mathrm{WH}$ profile. Among all the soil samples, the highest clay content was $49.09 \%$ (J08), while the lowest clay content was only 
$27.10 \%$ (J02). In addition, the variation range of clay fraction in the JU profile (22\%) was larger than that of the YE and WH profiles (6.93\% and $10.21 \%$, respectively).

Table 1. Basic physical and chemical properties of plinthosol.

\begin{tabular}{|c|c|c|c|c|c|c|c|c|c|c|c|}
\hline \multicolumn{4}{|c|}{ WH } & \multicolumn{4}{|c|}{$\mathrm{JU}$} & \multicolumn{4}{|c|}{ YE } \\
\hline ID & $\begin{array}{c}\mathrm{BD}^{*} \\
\left(\mathrm{~g} \cdot \mathrm{cm}^{-3}\right)\end{array}$ & $\begin{array}{c}\mathrm{OM}^{*} \\
\left(\mathrm{~g} \cdot \mathrm{kg}^{-1}\right)\end{array}$ & $\begin{array}{l}\text { Porosity } \\
\left(\mathrm{cm}^{3} \cdot \mathrm{cm}^{-3}\right)\end{array}$ & ID & $\begin{array}{c}\text { BD } \\
\left(\mathrm{g} \cdot \mathrm{cm}^{-3}\right)\end{array}$ & $\begin{array}{c}\mathrm{OM} \\
\left(\mathrm{g} \cdot \mathrm{kg}^{-1}\right)\end{array}$ & $\begin{array}{l}\text { Porosity } \\
\left(\mathrm{cm}^{3} \cdot \mathrm{cm}^{-3}\right)\end{array}$ & ID & $\begin{array}{c}\text { BD } \\
\left(\mathrm{g} \cdot \mathrm{cm}^{-3}\right)\end{array}$ & $\begin{array}{c}\mathrm{OM} \\
\left(\mathrm{g} \cdot \mathrm{kg}^{-1}\right)\end{array}$ & $\begin{array}{l}\text { Porosity } \\
\left(\mathrm{cm}^{3} \cdot \mathrm{cm}^{-3}\right)\end{array}$ \\
\hline W01 & 1.55 & 5.90 & 0.41 & J01 & 1.30 & 5.88 & 0.51 & Y01 & 1.20 & 3.83 & 0.55 \\
\hline W02 & 1.60 & 2.35 & 0.40 & J02 & 1.36 & 7.53 & 0.48 & Y02 & 1.23 & 3.06 & 0.54 \\
\hline W03 & 1.56 & 2.01 & 0.41 & J03 & 1.37 & 5.51 & 0.48 & Y03 & 1.38 & 3.19 & 0.48 \\
\hline W04 & 1.62 & 2.29 & 0.39 & J04 & 1.42 & 5.54 & 0.46 & Y04 & 1.37 & 2.74 & 0.48 \\
\hline W05 & 1.61 & 2.31 & 0.39 & J05 & 1.46 & 6.44 & 0.45 & Y05 & 1.34 & 2.16 & 0.49 \\
\hline W06 & 1.57 & 3.07 & 0.41 & J06 & 1.50 & 4.03 & 0.43 & Y06 & 1.48 & 2.33 & 0.44 \\
\hline W07 & 1.52 & 3.51 & 0.43 & J07 & 1.56 & 3.01 & 0.41 & Y07 & 1.37 & 2.99 & 0.48 \\
\hline W08 & 1.54 & 3.54 & 0.42 & J08 & 1.65 & 2.48 & 0.38 & Y08 & 1.45 & 2.75 & 0.45 \\
\hline W09 & 1.52 & 3.65 & 0.43 & J09 & 1.63 & 3.46 & 0.38 & Y09 & 1.54 & 4.11 & 0.42 \\
\hline W10 & 1.50 & 3.75 & 0.43 & J10 & 1.60 & 2.85 & 0.40 & & & & \\
\hline
\end{tabular}

* The BD and OM are bulk density and organic matter content, respectively.

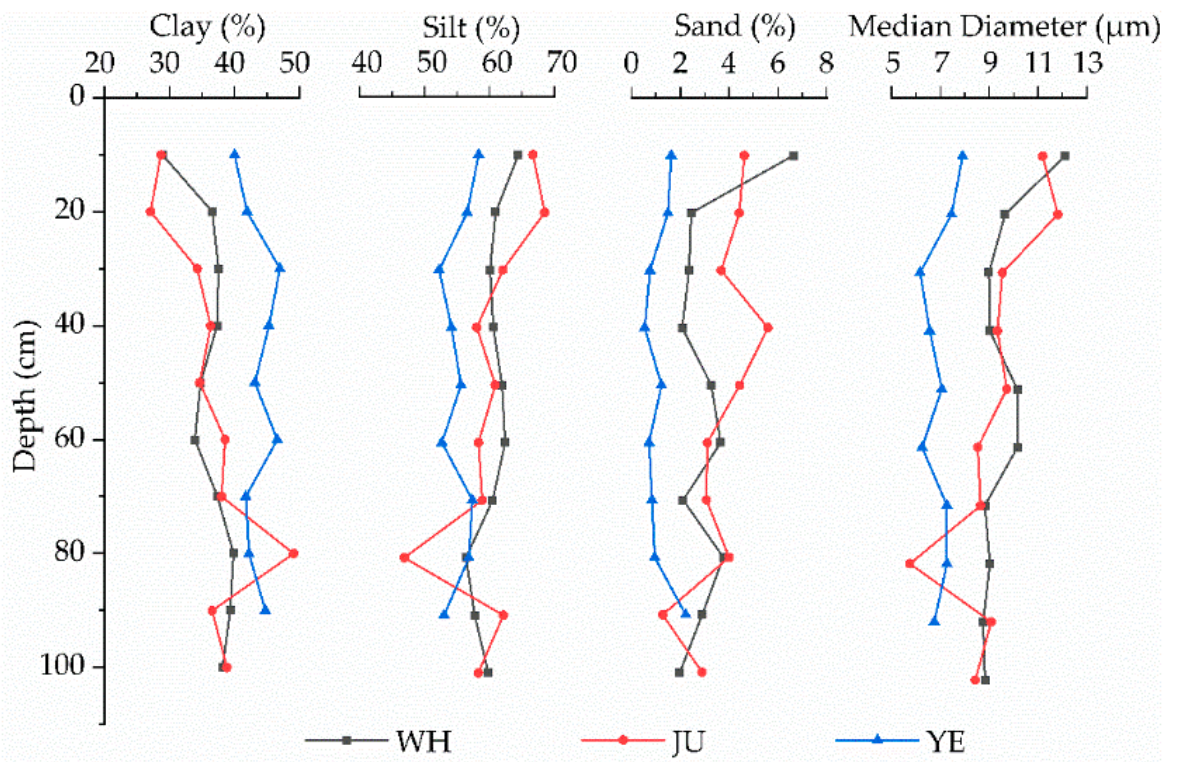

Figure 4. Particle size distribution of the Wuhan (WH), Jiujiang (JU), and Yueyang (YE) profiles.

Each datum is the average of three measurements.

Particle size composition could be used to distinguish the origin of sediments via discriminant analysis. Figure 5 shows the result of discriminant analysis on the plinthosol samples of the JU, WH, and YE profiles. According to Equation (9), generally speaking, the discriminant value of -2.7411 is the boundary between aeolian and alluvial origin [42]. As Figure 5 shows, the range of $Y$ value in the JU profile was -12.37 to 6.94 , which was larger than that in the WH (1.44 to 9.27) and YE (6.13 to 11.45) profiles. Most samples in JU profile were lower than -2.7411, while in the WH and YE profiles, all the $Y$ values were higher than -2.7411 . This result indicates that the origin of plinthosol in the JU profile might be aeolian sediments, and the origin of plinthosol in the WH and YE profiles might be alluvial sediments. It also indicates a relatively stable deposition process in the WH and YE profiles. 


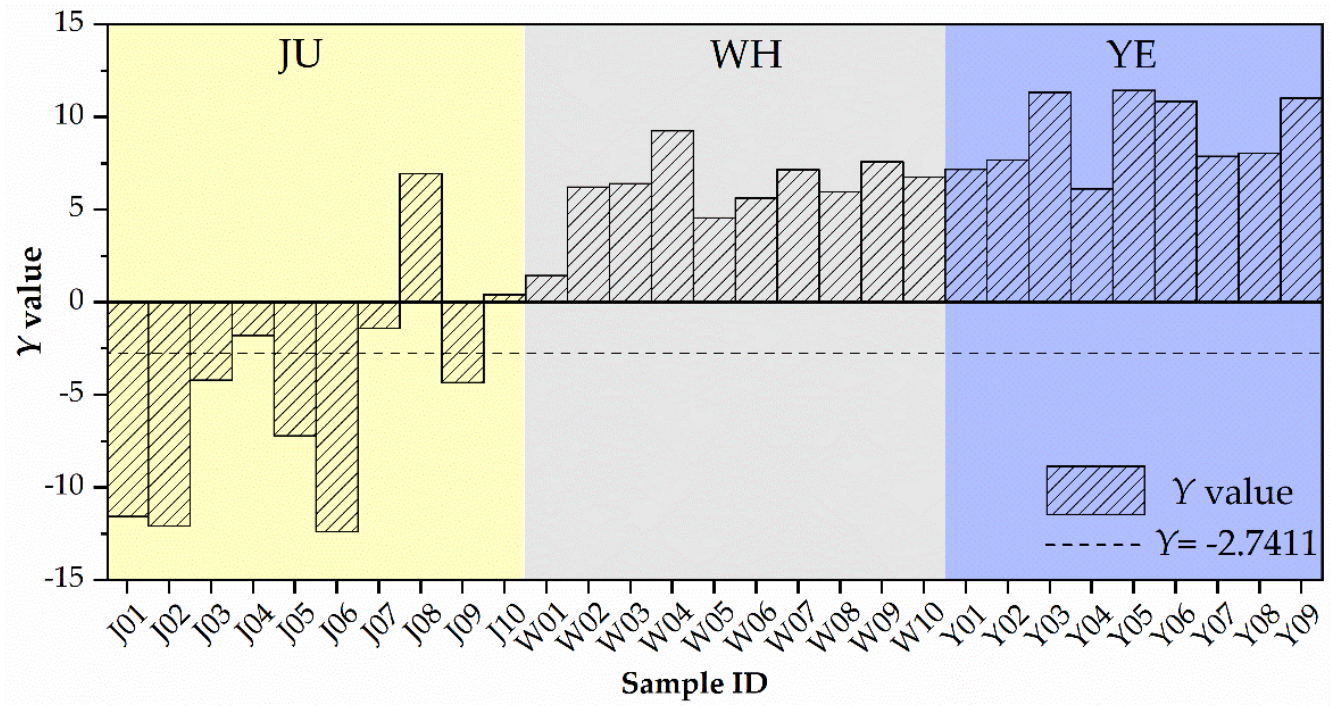

Figure 5. The discriminant parameter value $(Y)$ of plinthosol in the JU, WH, and YE profiles.

\subsection{Water Stable Aggregates (WSA)}

In this study, water-stable aggregates were categorized into six groups ( $>5 \mathrm{~mm}, 2-5 \mathrm{~mm}, 1-2 \mathrm{~mm}$, $0.5-1 \mathrm{~mm}, 0.25-0.5 \mathrm{~mm}$, and $<0.25 \mathrm{~mm}$ ), and their relative proportions are shown in Figure 6 . Some basic information could be extracted from a glance at this figure. For example, the proportions of macro-aggregates $(>0.25 \mathrm{~mm})$ and micro-aggregates $(<0.25 \mathrm{~mm})$ varied widely between the JU, $\mathrm{WH}$, and YE profiles. In the JU profile, the proportion of macro-aggregates was higher, and that of micro-aggregates was lower than those in the YE and WH profiles. As for the proportion of each group, micro-aggregates dominated the YE profile, while the $0.5-1 \mathrm{~mm}$ group and micro-aggregates dominated the $\mathrm{WH}$ profile. The $>5 \mathrm{~mm}$ group accounted for the largest proportion in the JU profile. The fractions of WSA indicated soil water stability. The more macro-aggregates, the stronger the anti-erodibility. Therefore, the plinthosol in the JU profile exhibited better anti-erodibility than that in the WH and YE profiles, and that of the YE profile was the weakest, which could also be supported by mean weight diameter $(M W D)$ and geometric mean diameter $(G M D)$.

$\mathrm{JU}$

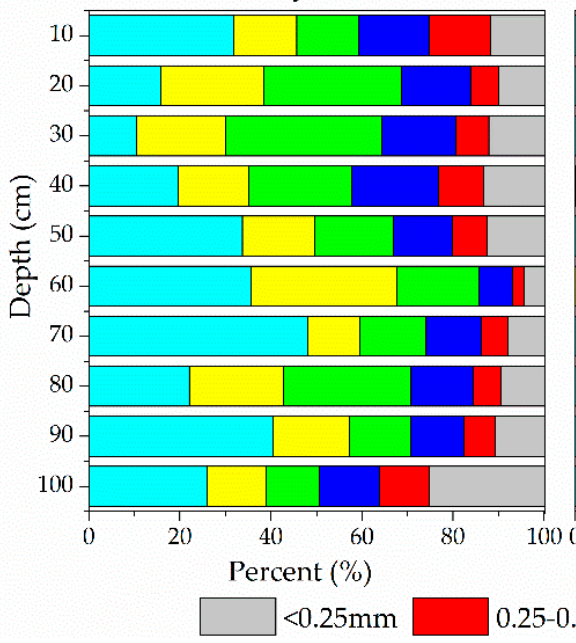

WH

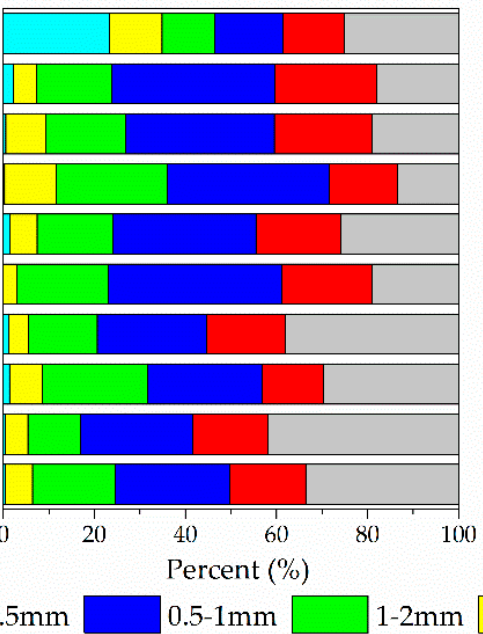

YE

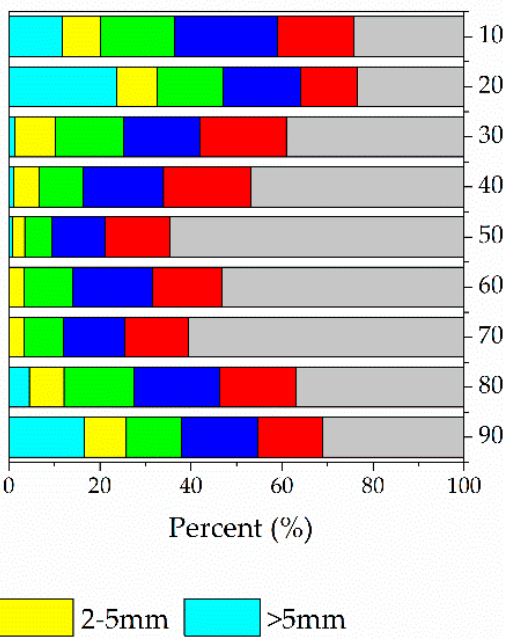

Figure 6. Relative proportion of water-stable aggregates (WSA) in the JU, WH and YE profile.

As shown in Figure 7, the general shape of the GMD curve is similar to that of the MWD curve, and the value of $G M D$ is lower than that of $M W D$. In the top layer $(0-20 \mathrm{~cm})$, the average values of $M W D$ in the JU, WH and YE profiles are $1.72 \mathrm{~mm}, 1.74 \mathrm{~mm}$, and $2.12 \mathrm{~mm}$, respectively, higher than 
that in the middle $(30-70 \mathrm{~cm})$ and bottom layer $(>70 \mathrm{~cm})$. According to the classes of stability and crustability, $0.4<M W D<0.8$ is unstable, $0.8<M W D<1.3$ is medium, $1.3<M W D<2.0$ is stable, and $M W D>2.0$ is very stable [47]. The soil aggregates of the top layer in the study profiles were at a stable or very stable level. Besides, for the WH and YE profiles, the mean values of MWD in the middle layer were only $0.91 \mathrm{~mm}$ and $0.62 \mathrm{~mm}$, respectively, indicating a medium and unstable level. Moreover, the MWD and GMD in the JU profile were higher than those in the WH and YE profiles in the middle and bottom layers.

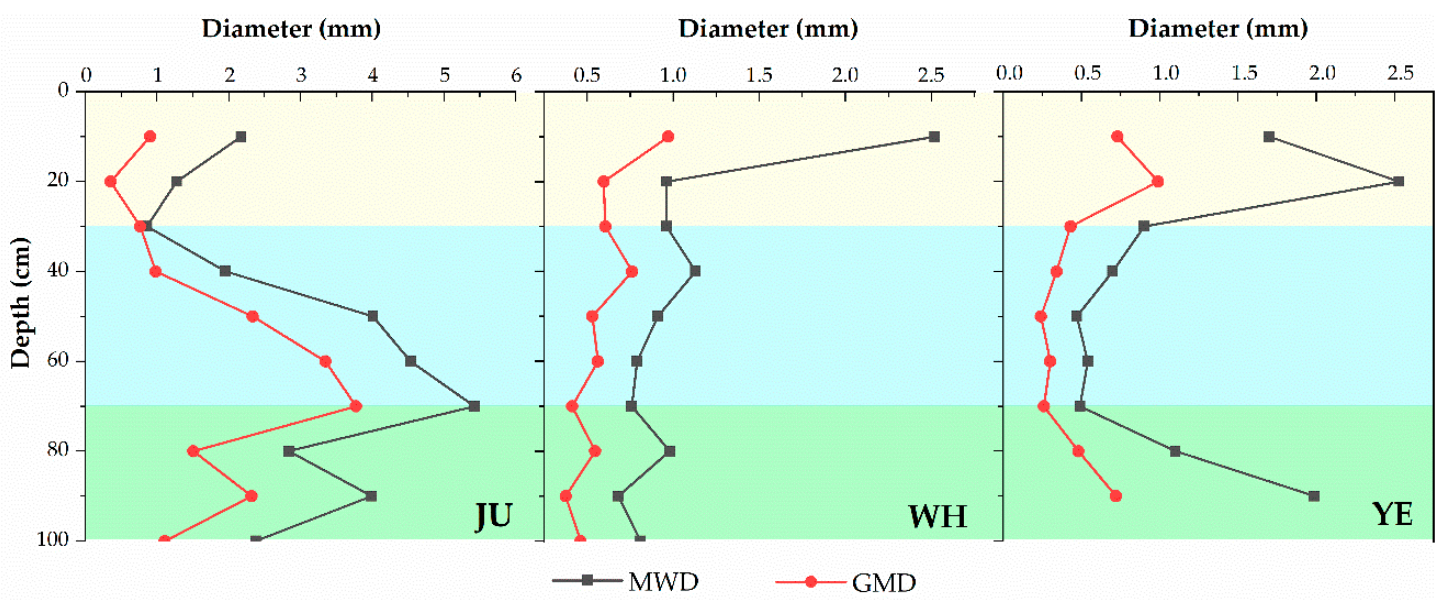

Figure 7. Mean weight diameter $(M W D)$ and geometric mean diameter $(G M D)$ of plinthosol in the JU, $\mathrm{WH}$, and YE profiles.

The fractal dimension of WSA was shown in Figure 8. Generally, a lower $D$ value indicates a stronger stability $[37,38]$. In the WH and YE profiles, the $D$ value of the upper layer was higher than that in the middle and bottom layers, which indicates strong stability in the upper layer. In the JU profile, the $D$ value is lower than that in the WH and YE profiles; the lowest $D$ value appeared at the depth of $60 \mathrm{~cm}$, demonstrating that the stability of plinthosol in the JU profile was the highest among the sampled profiles. The results of the fractal dimension strongly support the result of the WSA content.

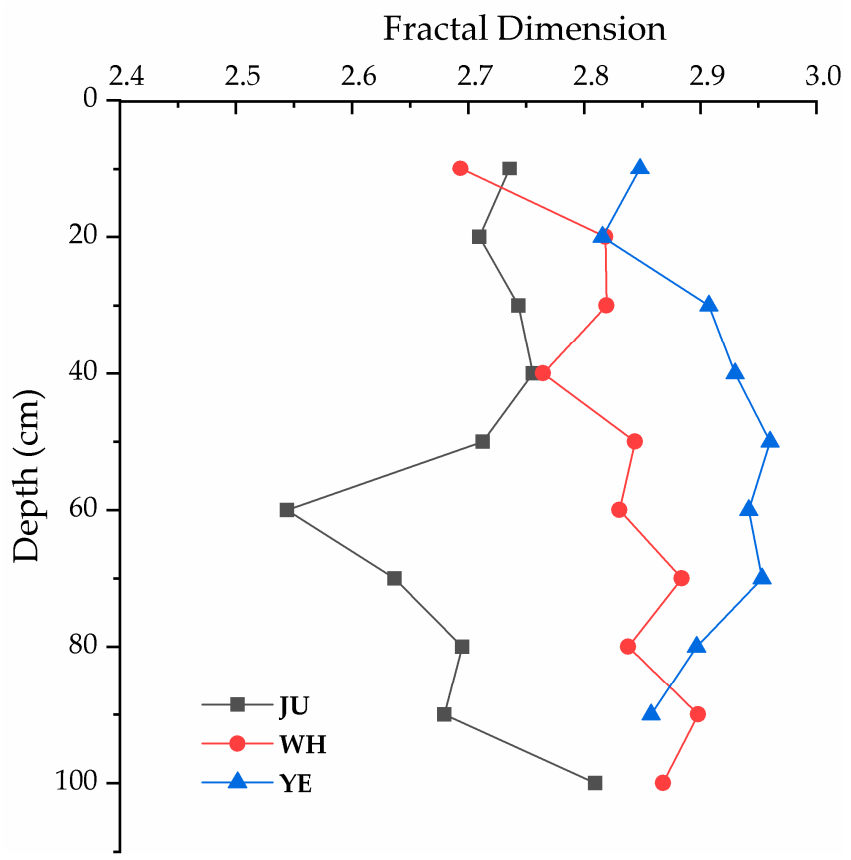

Figure 8. Fractal dimension $(D)$ of WSA in the JU, WH, and YE profiles. 
The water stability of the white vein and red matrix demonstrated obvious differences in the three profiles (Figure 9). In the red matrix, for example, the $>5 \mathrm{~mm}$ WSA content in the JU profile was $57.4 \%$, while in the $\mathrm{WH}$ and YE profiles, the values were only $9.2 \%$ and $0.0 \%$, respectively, meaning the water stability of the red matrix in the JU profile was better than that of the other two profiles. However, the water stability of the white vein in the JU profile was extremely poor. As Figure 9 shows, the content of micro-aggregates $(<0.25 \mathrm{~mm})$ was $75.78 \%$ in the JU profile, while in the $\mathrm{WH}$ and YE profiles it was only $49.8 \%$ and $25.62 \%$, respectively.

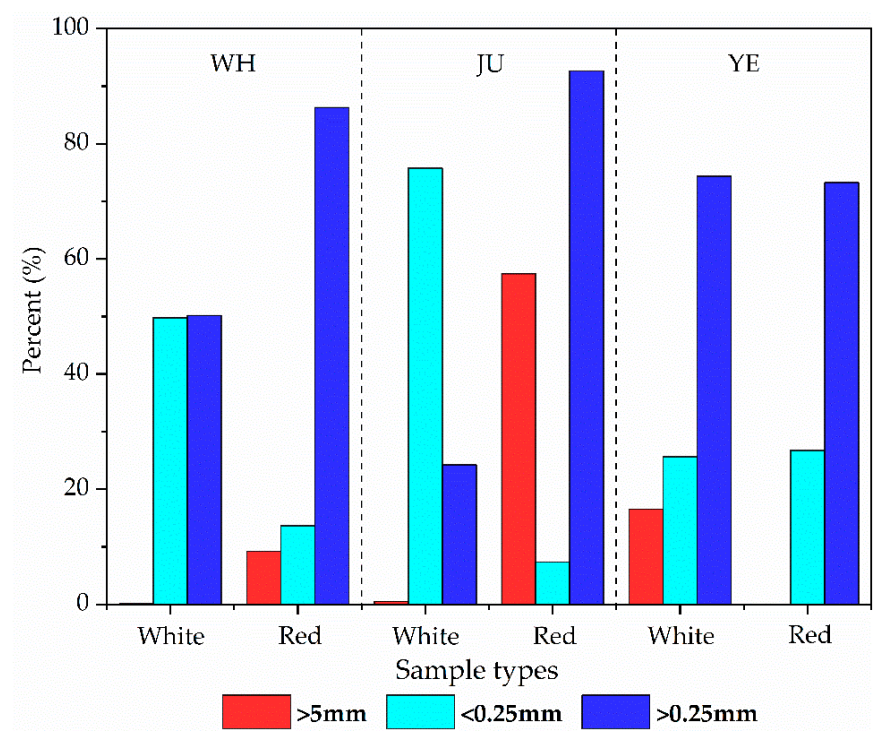

Figure 9. The aggregates content of red matrix and white vein. In this figure, "White" represents white vein, and "Red" represents red matrix.

\subsection{Saturated Hydraulic Conductivity $\left(K_{s}\right)$}

With the increase of bulk density, the porosity decreased, and the $K_{s}$ of the three profiles decreased with depth (Figure 10). Statistical analysis further suggested that the $K_{s}$ value varied significantly $(p<0.05)$ among soil depths in all the profiles. The highest $K_{s}$ arose in the top layer $(0-10 \mathrm{~cm})$, and the lowest value appeared in the bottom half of the profile $(80-90 \mathrm{~cm}$ in WH, $40-50 \mathrm{~cm}$ in YE, and 70-80 in JU). A special case is J08 in the JU profile, which deviated from the "normal" trend and decreased sharply. Data analysis also revealed that the soil saturated hydraulic conductivity had a wide discrepancy between the JU, WH, and YE profiles. The mean value of each profile was $4.57 \mathrm{~cm} / \mathrm{d}$, $1.23 \mathrm{~cm} / \mathrm{d}$, and $3.54 \mathrm{~cm} / \mathrm{d}$, respectively. The infiltration capacity of the JU profile was higher than that of the WH and YE profiles.

The relationship between $K_{s}$ values and GMD, MWD, and OM contents is shown in Table 2. In the WH and YE profiles, a positive correlation between these parameters was detected. Especially in the WH profile, the correlation coefficients between $K_{s}$ values and GMD and between $K_{s}$ values and MWD reached 0.8313 and 0.9794 , respectively. However, the correlation between these parameters was not as obvious in the JU profile; the correlation coefficients were only -0.3049 and -0.3497 , respectively. This result might suggest that the stability of water-stable aggregates relates to the saturated water conductivity in the alluvial sediments, while it is not as obvious in the eolian deposits. The result shows a strong positive correlation between the $K_{s}$ values and OM contents in Table 2, which confirmed that the $K_{s}$ values of soil were indeed affected by the OM contents. 


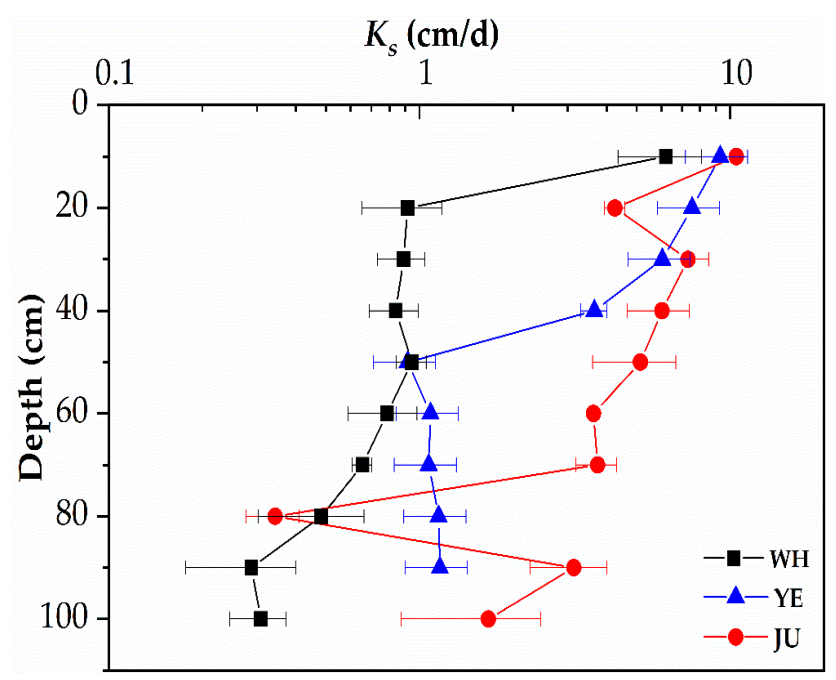

Figure 10. Saturated water conductivity $\left(K_{s}\right)$ in the $\mathrm{WH}, \mathrm{YE}$, and JU profiles.

Table 2. The correlation between $K_{S}$ values and $G M D, M W D$, and OM contents of the plinthosol samples.

\begin{tabular}{cccc}
\hline Correlation Coefficient & JU & WH & YE \\
\hline GMD & -0.3049 & 0.8313 & 0.6450 \\
MWD & -0.3497 & 0.9794 & 0.5650 \\
OM & 0.7386 & 0.6475 & 0.5372 \\
\hline
\end{tabular}

\subsection{Soil Water Retention Curve (SWRC)}

The relationship between soil volumetric water content and matric suction is shown in Figure 11. Under a given suction, the soil water-holding capacity curves of each layer in the WH profile were relatively close to each other; the gap between these curves was not as large as it was in the YE and JU profiles. From W01 to W10, the SWRCs of the samples demonstrated no significant difference, but further investigation revealed that the water-holding capacity of plinthosol increased with depth, which means that the water-holding capacity of the upper layer was weaker than that of the lower layer. This trend was also detected in the YE and JU profiles.

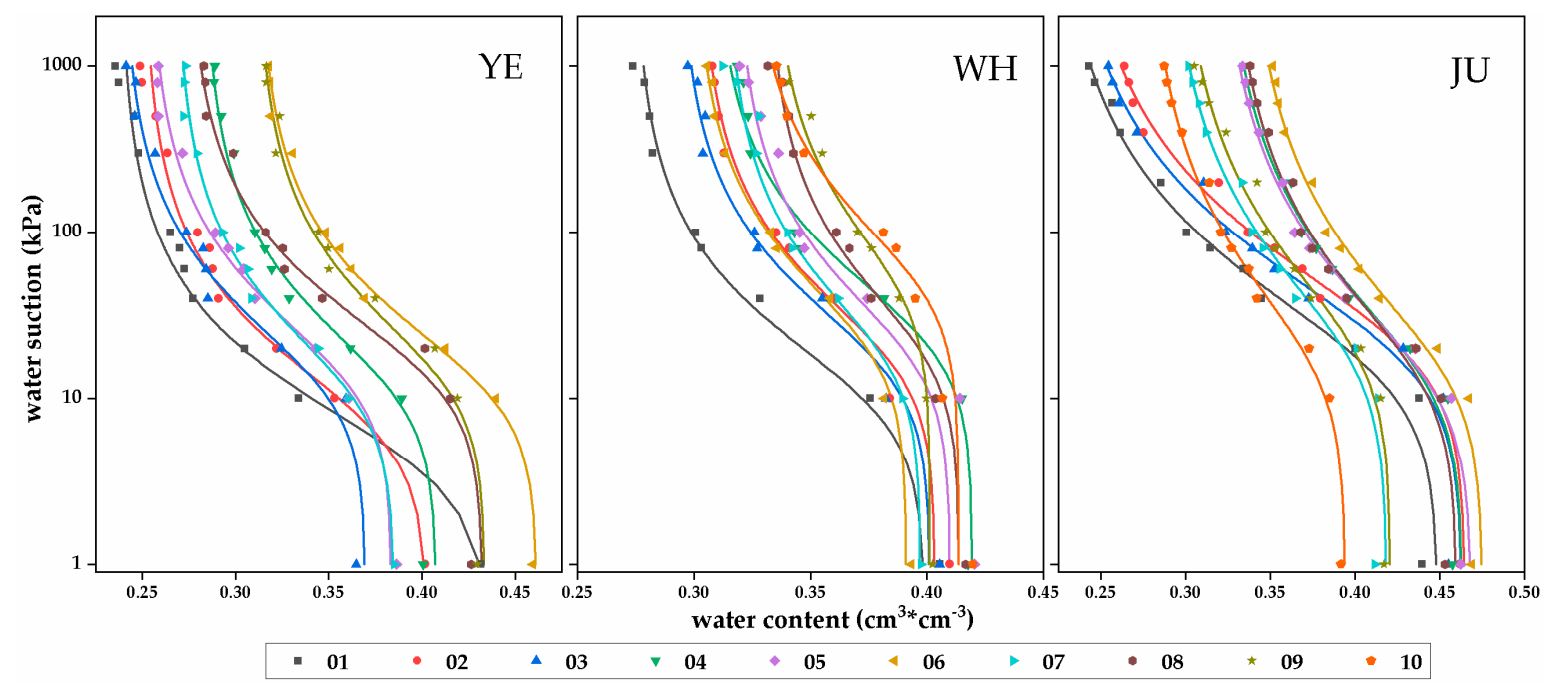

Figure 11. Soil water retention curves (SWRCs) of the YE, WH, and JU profiles. In this figure, the colored dots represent the measured data, and the lines represent the fitted curve using the van Genuchten ( $m=1-1 / n)$ model. At the bottom of this figure, a series of colored points numbered from 01 to 10 represents the sampled soil layers from 1-10 cm to $90-100 \mathrm{~cm}$ (only 9 layers in the YE profile). 
Moreover, as soil-water suction and depth increased, the SWRCs of the JU, WH, and YE profiles displayed synchronous fluctuations. Taking the JU profile as an example, the profile could be divided into three sections according to the variation of water-holding capacity. The upper layer (J01-J03) showed high water retention capacity at low suction (i.e., 0-200 kPa), but poor water retention capacity at high suction (i.e., $>400 \mathrm{kPa}$ ). The second layer (J04-J06) showed strong water-holding capacity over the whole suction range. The third layer (J07-J10) showed poor water retention capacity over the whole suction range, but still higher than that of the upper layer. The division of this profile by soil water-holding capacity is similar to the division by appearance during the field survey.

Under $10 \mathrm{kPa}$ suction, the mean volumetric water content in the JU profile (0.43) was higher than that in the YE (0.36) and $\mathrm{WH}(0.39)$ profiles. The variation of water content between different layers in the $\mathrm{WH}$ profile was the lowest. In the $\mathrm{WH}$ profile, the range of water content was from 0.35 (W01) to 0.43 (W10), which was smaller than that of the JU and YE profiles. By contrast, the range of water content in YE profile was from 0.31 (Y01) to 0.40 (Y09), which means the biggest difference of soil layers among all the three profiles.

The parameters $\theta_{r}, \theta_{s}, \alpha, n$, and $m$ were obtained by running a computer program named RETC. The fitted parameters and fitting accuracy are shown in Table 3. $\alpha\left(\mathrm{cm}^{-1}\right)$ and $n$ are model parameters; $m=1-1 / n$. In the YE profile, the mean residual and saturated water contents were higher than those in the $\mathrm{WH}$ and JU profiles. The clay content should be primarily responsible for this difference. The parameters $\alpha\left(\mathrm{cm}^{-1}\right)$ and $n$ are related to the inverse of air entry value and pore size distribution, respectively [41,48]. In this study, the values of the fitting parameter $\alpha$ vary at different layers and decrease with depth. However, the variation of $\alpha$ is different among the study sites. The higher the $\alpha$ value, the lower the air-entry value. In this study, the highest air-entry value is in the WH profile, which might be due to the proportion of soil aggregates, while the lowest $n$ value appeared in the YE profile, which might also be related to the finer particle composition.

Table 3. The fitted parameters and fitting accuracy of SWRC *.

\begin{tabular}{|c|c|c|c|c|c|c|c|c|}
\hline Profile & ID & $\theta_{r}$ & $\theta_{s}$ & $\alpha$ & $n$ & $m$ & $R^{2}$ & $R M S D$ \\
\hline \multirow{10}{*}{ WH } & W01 & 0.080 & 0.415 & 0.007 & 1.526 & 0.345 & 0.986 & 0.008 \\
\hline & W02 & 0.086 & 0.419 & 0.009 & 1.433 & 0.302 & 0.997 & 0.005 \\
\hline & W03 & 0.088 & 0.429 & 0.009 & 1.434 & 0.302 & 0.990 & 0.007 \\
\hline & W04 & 0.085 & 0.414 & 0.010 & 1.418 & 0.295 & 0.987 & 0.012 \\
\hline & W05 & 0.083 & 0.412 & 0.009 & 1.446 & 0.308 & 0.938 & 0.006 \\
\hline & W06 & 0.084 & 0.420 & 0.009 & 1.467 & 0.318 & 0.991 & 0.005 \\
\hline & W07 & 0.089 & 0.442 & 0.009 & 1.446 & 0.309 & 0.930 & 0.005 \\
\hline & W08 & 0.090 & 0.435 & 0.010 & 1.414 & 0.293 & 0.976 & 0.003 \\
\hline & W09 & 0.090 & 0.442 & 0.010 & 1.425 & 0.298 & 0.946 & 0.003 \\
\hline & W10 & 0.090 & 0.446 & 0.010 & 1.440 & 0.306 & 0.982 & 0.006 \\
\hline \multirow{10}{*}{ JU } & $\mathrm{J} 01$ & 0.081 & 0.454 & 0.008 & 1.534 & 0.348 & 0.996 & 0.014 \\
\hline & $\mathrm{J} 02$ & 0.077 & 0.433 & 0.008 & 1.546 & 0.353 & 0.993 & 0.011 \\
\hline & $\mathrm{J} 03$ & 0.087 & 0.452 & 0.010 & 1.469 & 0.319 & 0.993 & 0.011 \\
\hline & J04 & 0.087 & 0.442 & 0.011 & 1.431 & 0.301 & 0.994 & 0.009 \\
\hline & J05 & 0.087 & 0.455 & 0.011 & 1.459 & 0.315 & 0.994 & 0.011 \\
\hline & J06 & 0.086 & 0.426 & 0.012 & 1.394 & 0.283 & 0.993 & 0.009 \\
\hline & J07 & 0.089 & 0.451 & 0.011 & 1.425 & 0.298 & 0.990 & 0.008 \\
\hline & J08 & 0.086 & 0.396 & 0.016 & 1.253 & 0.202 & 0.989 & 0.010 \\
\hline & J09 & 0.085 & 0.399 & 0.014 & 1.290 & 0.225 & 0.989 & 0.005 \\
\hline & $\mathrm{J} 10$ & 0.082 & 0.401 & 0.012 & 1.359 & 0.264 & 0.992 & 0.006 \\
\hline \multirow{9}{*}{ YE } & Y01 & 0.097 & 0.517 & 0.012 & 1.420 & 0.296 & 0.987 & 0.008 \\
\hline & Y02 & 0.098 & 0.511 & 0.013 & 1.403 & 0.287 & 0.987 & 0.009 \\
\hline & Y03 & 0.047 & 0.386 & 0.011 & 1.515 & 0.340 & 0.986 & 0.012 \\
\hline & Y04 & 0.096 & 0.477 & 0.013 & 1.372 & 0.271 & 0.997 & 0.013 \\
\hline & Y05 & 0.096 & 0.482 & 0.013 & 1.392 & 0.282 & 0.994 & 0.008 \\
\hline & Y06 & 0.093 & 0.447 & 0.013 & 1.345 & 0.256 & 0.993 & 0.012 \\
\hline & Y07 & 0.094 & 0.474 & 0.012 & 1.406 & 0.289 & 0.987 & 0.009 \\
\hline & Y08 & 0.092 & 0.451 & 0.012 & 1.390 & 0.281 & 0.976 & 0.016 \\
\hline & Y09 & 0.089 & 0.426 & 0.013 & 1.338 & 0.253 & 0.967 & 0.012 \\
\hline
\end{tabular}

* The $\mathrm{R}^{2}$ and root mean square difference (RMSD) were calculated in this Table. $\theta_{r}$ and $\theta_{s}$ are the residual water content and the saturated water content, respectively. $\alpha\left(\mathrm{kPa}^{-1}\right), n$, and $m$ $(m=1-1 / n)$ are empirical parameters. 


\subsection{Soil Disintegration Rate $\left(D_{r}\right)$ and Disintegration Index $\left(D_{i}\right)$}

Soil $D_{r}$ and $D_{i}$ are important indices for measuring the behavior of soil disintegration. For the plinthosol in the JU, $\mathrm{WH}$, and YE profiles, the experimental testing and calculation results are presented in Table 4. For these profiles, the general trend of disintegration increased over time. In the YE profile, all samples completely disintegrated in $3600 \mathrm{~s}$. In the YE profile, all samples disintegrated at the end of the experiment, but some samples did not as easily disintegrate as the samples in the JU and WH profiles, especially J07 and W01. The $D_{i}$ values at $3600 \mathrm{~s}$ were only $21 \%$ and $0.25 \%$, and the $D_{r}$ values were only $0.05 \% \cdot \mathrm{s}^{-1}$ and $0.08 \% \cdot \mathrm{s}^{-1}$, respectively, showing the anti-erodibility was relatively strong, which was roughly the same as the content of macro-aggregates. The $D_{r}$ value of plinthosol in the YE profile $\left(0.32 \% \cdot \mathrm{s}^{-1}\right.$ on average) was higher than that of the JU and $\mathrm{WH}$ profiles $\left(0.24\right.$ and $0.29 \% \cdot \mathrm{s}^{-1}$, respectively), and the plinthosol in the JU profile was the lowest among the three profiles, illustrating the plinthosol in YE disintegrated more easily than in JU and WH.

Table 4. The soil disintegration rate $\left(D_{r}\right)$ and disintegration index $\left(D_{i}\right)$ of plinthosol.

\begin{tabular}{|c|c|c|c|c|c|c|c|c|c|c|c|}
\hline \multirow{2}{*}{ Sample } & \multicolumn{10}{|c|}{$D_{i} /$ Time (s) } & \multirow{2}{*}{$D_{r}\left(\% \cdot \mathrm{s}^{-1}\right)$} \\
\hline & 10 & 30 & 60 & 120 & 180 & 300 & 450 & 600 & 900 & 3600 & \\
\hline J01 & 0.00 & 0.04 & 0.17 & 0.44 & 0.52 & 0.56 & 0.68 & 0.70 & 0.71 & 0.76 & 0.19 \\
\hline J02 & 0.30 & 0.57 & 0.81 & 0.91 & 0.97 & 0.97 & 0.98 & 0.98 & 1.00 & 1.00 & 0.32 \\
\hline J03 & 0.03 & 0.97 & 0.98 & 0.98 & 1.00 & 1.00 & 1.00 & 1.00 & 1.00 & 1.00 & 0.33 \\
\hline J04 & 0.02 & 0.28 & 0.55 & 0.60 & 0.72 & 0.77 & 0.77 & 0.90 & 0.90 & 0.91 & 0.26 \\
\hline J05 & 0.18 & 0.34 & 0.47 & 0.58 & 0.72 & 0.74 & 0.79 & 0.79 & 0.83 & 0.83 & 0.25 \\
\hline J06 & 0.03 & 0.12 & 0.18 & 0.51 & 0.72 & 0.86 & 0.90 & 0.90 & 0.91 & 1.00 & 0.29 \\
\hline J07 & 0.00 & 0.00 & 0.00 & 0.06 & 0.12 & 0.14 & 0.15 & 0.19 & 0.19 & 0.21 & 0.05 \\
\hline J08 & 0.00 & 0.10 & 0.14 & 0.39 & 0.47 & 0.57 & 0.98 & 0.98 & 0.98 & 1.00 & 0.19 \\
\hline J09 & 0.00 & 0.24 & 0.52 & 0.62 & 0.68 & 0.79 & 0.84 & 0.87 & 0.86 & 1.00 & 0.26 \\
\hline $\mathrm{J} 10$ & 0.00 & 0.29 & 0.44 & 0.66 & 0.66 & 0.67 & 0.67 & 0.65 & 0.68 & 1.00 & 0.22 \\
\hline W01 & 0.10 & 0.23 & 0.25 & 0.25 & 0.25 & 0.25 & 0.25 & 0.25 & 0.25 & 0.25 & 0.08 \\
\hline W02 & 0.39 & 0.58 & 0.67 & 0.70 & 0.70 & 0.74 & 0.77 & 0.77 & 0.79 & 0.80 & 0.25 \\
\hline W03 & 0.16 & 0.56 & 0.77 & 0.85 & 0.90 & 0.96 & 0.97 & 0.97 & 0.97 & 0.97 & 0.32 \\
\hline W04 & 0.31 & 0.71 & 0.88 & 0.92 & 0.94 & 0.96 & 0.96 & 0.98 & 0.98 & 0.98 & 0.32 \\
\hline W05 & 0.12 & 0.65 & 0.91 & 0.96 & 0.98 & 1.00 & 1.00 & 1.00 & 1.00 & 1.00 & 0.33 \\
\hline W06 & 0.21 & 0.63 & 0.75 & 0.84 & 0.89 & 0.93 & 0.95 & 0.95 & 0.97 & 0.98 & 0.31 \\
\hline W07 & 0.03 & 0.08 & 0.19 & 0.45 & 0.75 & 1.00 & 1.00 & 1.00 & 1.00 & 1.00 & 0.33 \\
\hline W08 & 0.13 & 0.33 & 0.83 & 1.00 & 1.00 & 1.00 & 1.00 & 1.00 & 1.00 & 1.00 & 0.33 \\
\hline W09 & 0.13 & 0.25 & 0.42 & 0.70 & 0.79 & 0.84 & 1.00 & 1.00 & 1.00 & 1.00 & 0.28 \\
\hline W10 & 0.04 & 0.45 & 0.66 & 0.80 & 0.96 & 0.98 & 1.00 & 1.00 & 1.00 & 1.00 & 0.33 \\
\hline Y01 & 0.28 & 0.80 & 0.97 & 0.98 & 0.98 & 1.00 & 1.00 & 1.00 & 1.00 & 1.00 & 0.33 \\
\hline Y02 & 0.05 & 0.03 & 0.34 & 0.40 & 0.97 & 1.00 & 1.00 & 1.00 & 1.00 & 1.00 & 0.33 \\
\hline Y03 & 0.04 & 0.25 & 0.33 & 0.66 & 0.99 & 0.99 & 0.99 & 0.99 & 0.99 & 1.00 & 0.33 \\
\hline Y04 & 0.16 & 0.64 & 0.80 & 0.92 & 0.95 & 0.99 & 1.00 & 1.00 & 1.00 & 1.00 & 0.33 \\
\hline Y05 & 0.36 & 0.80 & 0.92 & 0.97 & 0.99 & 1.00 & 1.00 & 1.00 & 1.00 & 1.00 & 0.33 \\
\hline Y06 & 0.17 & 0.37 & 0.51 & 0.72 & 0.78 & 0.88 & 0.88 & 0.91 & 0.91 & 1.00 & 0.29 \\
\hline Y07 & 0.01 & 0.10 & 0.32 & 0.61 & 0.73 & 1.00 & 1.00 & 1.00 & 1.00 & 1.00 & 0.33 \\
\hline Y08 & 0.13 & 0.30 & 0.70 & 0.85 & 0.86 & 0.94 & 1.00 & 1.00 & 1.00 & 1.00 & 0.31 \\
\hline Y09 & 0.31 & 0.68 & 0.87 & 0.88 & 1.00 & 1.00 & 1.00 & 1.00 & 1.00 & 1.00 & 0.33 \\
\hline
\end{tabular}

Besides the differences in the disintegration process among each profile and layer, there was also some discrepancy between the red matrix and white vein in plinthosol (Figure 12). In the JU profile, all the white vein disintegrated in $1 \mathrm{~min}$, but for the red matrix, only $33.5 \%$ disintegrated in $10 \mathrm{~min}$. The gap between the white vein curve and red matrix curve was $66.7 \%$ (Figure $12 \mathrm{JU}$ ). However, for the WH and YE profiles, the discrepancy was not as large, only $6 \%$ and $2 \%$, respectively, and the disintegration rate in these two profiles was faster than that of the red matrix, but slower than that of the white vein in the JU profile. 


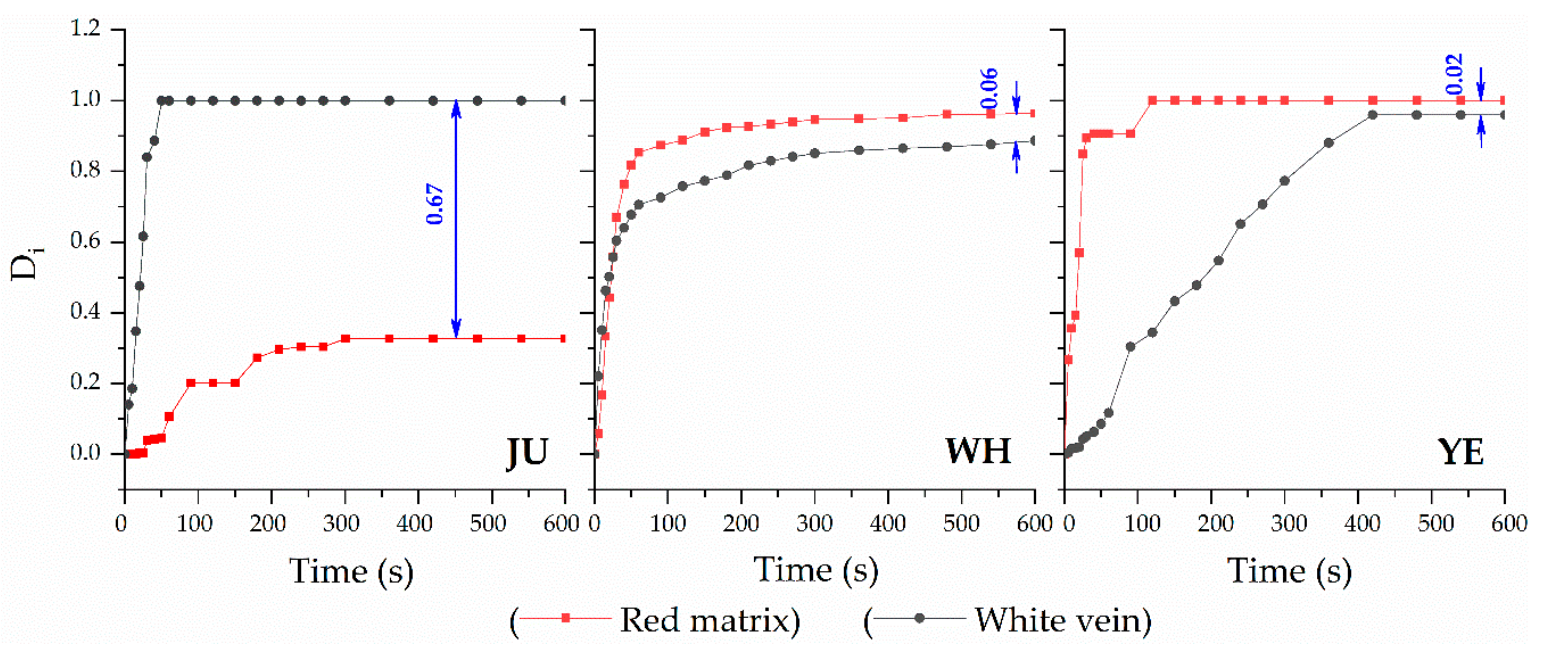

Figure 12. Disintegration index of red matrix and white vein with time.

\section{Discussion}

\subsection{Effect of Soil Origin on Soil Hydraulic Properties}

Previous studies have suggested that the plinthosol might derive from multiple origins. In the mid-subtropical area, the plinthosol is of aeolian or alluvial origin, and it suffered from strong weathering processes during and after sedimentation [13]. The origin affects soil particle size distribution, and particle size plays an important role in soil porosity, bulk density, WSA content, SWRC, $K_{s}, D_{r}$, and $D_{i}$ [49]. According to the discriminant analysis (Figure 5), the origin of the JU profile is aeolian deposits and that of the WH and YE profiles is alluvial deposits. Moreover, some indices of soil hydraulic properties also support this judgement. For example, the $K_{s}$ value in the JU profile is higher than those in the WH and YE profiles (Figure 10). Previous studies showed $K_{S}$ is related to soil bulk density and porosity [50]. The hydraulic conductivity of fine-grained alluvial deposits is relatively low because of its compact structure [51,52]. However, $K_{S}$ is a little bit higher in aeolian sediment due to its loose structure, especially the pore size continuity [27]. During the aeolian sedimentary process, many pores were produced, and numerous vertical tubular channels were formed [53], these tubular channels are continuous tubes, which result in high water conductivity.

Besides, the curves of the disintegration process of plinthosol in the JU profile, especially the red matrix and white vein, are quite different from those in the WH and YE profiles (Figure 12). Nevertheless, the discrepancy between red matrix and white vein in the JU profile might be due to the particle distribution, rather than the origin [3]. Particle size analysis showed that the white vein contained more fine particles than the red matrix. The clay contents of white vein and red matrix were $35.29 \%$ and $27.58 \%$, respectively. The finer the particles, the slower the disintegration rate [54] and, moreover, maybe the better the soil quality.

As an important parameter in predicting the soil erodibility factor and, hence, inter-rill erosion [38], the fractal dimension of soil aggregates also reflects the soil disintegration resistance. Generally, a lower value of fractal dimension implies a better disintegration resistance. In this study, the value of fractal dimension in JU was lower than that in WH and YE, which indicates that the stability of JU plinthosol was better than that of WH and YE plinthosol. Since the study area suffers from severe soil erosion, our result is helpful for calculating the resistance of soil erodibility and taking corresponding soil conservation measurements in different regions.

Soil quality encompasses several facets of soil function; one of them is the stability of WSA [33]. High-quality aggregates, silt, and clay could improve soil anti-erodibility [55]. In this study, the macro-aggregates content and values of GMD and MWD in WH and YE plinthosol were lower than in JU plinthosol, meaning the aggregate stability of plinthosol in the JU profile was the strongest among the three profiles (Figures 6 and 7). The results of fractal dimension also confirmed our 
inference (Figure 8). However, the particle size composition seemed at odds with the results above. As Figure 4 shows, the profile which possessed the highest clay content was the YE profile, not the JU profile. Considering the fact that soil aggregate stability is affected by many factors, such as plant roots, the activities of soil fauna and microorganisms, wetting and drying, or freeze-thaw cycles [51], the appropriate explanation might be derived from the above factors, which needs further studies.

\subsection{Red Matrix and White Vein on Soil Hydraulic Properties}

The visible difference between plinthosol and red clay is that the plinthosol contains worm-like white vein, which irregularly embedded in the red matrix, while there is no white vein in red clay [10]. The iron content in the white vein is roughly ten times lower than that in the red matrix, and the clay minerals content is lower and the quartz content is higher in the white vein than those in the red matrix $[8,10,11]$. Besides, there are also some differences in other geochemical components and microstructure between white vein and red matrix [25]. Due to the above differences and spatial variability, it is inappropriate to predict the hydraulic properties of plinthosol just by particle size distribution [56]. The clay type and content, ratio of white vein, soil structure, and some other factors may directly or indirectly affect the soil hydraulic parameters.

In the JU profile, there was a large discrepancy in soil hydraulic properties between the white vein and the red matrix: the disintegration process of the white vein was much more rapid than that of the red matrix (Figure 12); for the JU white vein, the content of macro-aggregates was only $24.22 \%$, while in the $\mathrm{WH}$ and YE profiles, the values were $50.20 \%$ and $74.38 \%$, respectively (Figure 9). Meanwhile, for the JU red matrix, the content of macro-aggregates was $92.63 \%$, while in the WH and YE profiles, the values were $86.32 \%$ and $73.27 \%$, respectively, indicating that the water stability of the red matrix was superior to that of the white vein. However, although the JU plinthosol comprised a certain proportion of white vein, it demonstrated the best water stability among the three profiles (Figure 6), which could be ascribed to the high proportion of red matrix and its strong stability. Besides, the proportion of macro-aggregates could be used to measure the susceptibility to runoff and erosion [57]. Thus, this result suggests that the anti-erodibility of JU plinthosol was higher than that of WH and YE plinthosol.

Compared with JU plinthosol, the discrepancy in soil hydraulic properties between white vein and red matrix was not as large in WH and YE plinthosol. Especially in the YE profile, the proportions of macro-aggregates in white vein and red matrix were $74.4 \%$ and $73.3 \%$, respectively; in the $\mathrm{WH}$ profile, the disintegration curves of white vein and red matrix were almost synchronous (Figure 12). The differences among these profiles might be attributed to the origins, deposition processes or pedogenesis. Previous studies suggested that the proportion of WSA might be closely related to clay content and weathering degree $[58,59]$, and the analysis of geochemical parameters and its spatial distribution would support our study.

\subsection{Soil Properties and Their Significance for Environmental Evolution}

Clay minerals are layer silicates formed as products of progressive chemical weathering [60]. Chronological studies indicated that plinthosol was formed under humid and warm climatic conditions during the mid-Pleistocene [10]. Generally, this type of climate is accompanied by strong weathering. Plinthosol is thought to have been produced by strong pedogenesis with intense oxidation and leaching, which resulted from enhanced East Asian summer monsoon activity [11]. In the studies of plinthosol, the particle size distribution was frequently used as a parameter to characterize the weathering intensity [12,49]. The content of fine-particle fractions will increase with weathering, and this process greatly affects the hydraulic properties of plinthosol $[15,61]$. In this study, the fine-particle fraction in YE plinthosol was higher than that in WH and JU plinthosol (Figure 4). However, this phenomenon does not really indicate the weathering is stronger in YE profile than that of the other two profiles. According to the climate zone in China, all the three profiles are located in the middle subtropical climate zone. The mean annual precipitation and temperature of the profiles are close to each other. If the plinthosol of the three profiles had developed simultaneously, it is easy to infer that 
the three sites shared a similar paleoclimate, and the weathering degree would also be similar. If so, the main cause of the difference may be ascribed to the initial particle size or weathering resistance of the deposition [56]: that is to say, the alluvial deposition from Dongting Lake (YE) might be finer or more prone to breakdown than that from the Yangtze river (WH), and it is also finer or more prone to breakdown than the aeolian sedimentation in JU. However, if the plinthosol of the three profiles developed asynchronously, the paleoclimate might have been wetter and warmer when the YE plinthosol developed, and drier and cooler when the WH and JU plinthosol developed.

Besides particle composition, the SWRCs might also reflect the environmental revolution [62]. When the suction was relatively high $(>400 \mathrm{kPa})$, the curves in JU plinthosol were more dispersed than those in the other two profiles (Figure 11). The wide range of soil water holding capacity indicates the deposition covered a long period of deposition, and the paleoclimate varied frequently during the deposition process. Contrary to JU plinthosol, the curves in WH plinthosol showed a compact shape in the high suction $(>400 \mathrm{kPa})$. Most of the curves were close to each other and might indicate a stable sedimentary environment. These assumptions need further study on the chemical elements of plinthosol or dating work at the sampling sites.

\section{Conclusions}

This study focused on the soil water hydraulic properties of the plinthosol in the Middle Yangtze River basin. Three typical profiles were sampled and studied. The main conclusions are summarized as follows:

(1) Discriminant analysis showed, in the JU profile, the range of $Y$ values was -12.37 to 6.94, and most samples were lower than -2.7411 , while in the WH and YE profiles, all $Y$ values were higher than -2.7411 . This result indicates that the origin of JU plinthosol is aeolian sediments, while in the WH profile and the YE profile, the origin might be alluvial deposition.

(2) The difference of soil origin affects the soil hydraulic properties. The macro-aggregates content of the JU profile was relatively higher than that of the YE and $\mathrm{WH}$ profiles, while $D_{i}$ and $D_{r}$ were lower in JU plinthosol. Fractal dimension analysis showed the $D$ value of JU plinthosol was lower than that of WH and YE plinthosol, which confirmed that the stability of JU plinthosol was superior to that of the other two sites.

(3) Soil origin plays a basic role in soil particle size distribution, which affects the water holding capacity, soil stability, hydraulic conductivity, and soil-water holding capacity. Meanwhile, soil hydraulic conductivity has a strong correlation with the organic matter contents.

(4) The water stability of white vein and red matrix showed great differences. The particle size composition and the proportion of white vein and red matrix played an important role in the difference of soil hydraulic properties.

This study confirmed the multiple origins of plinthosol in the Middle Yangtze River basin, and different origins may have resulted in the differences in soil hydraulic properties. These findings about plinthosol in hydraulic conductivity, water-holding capacity, and disintegration resistance could provide implications for vegetation construction and soil and water conservation in the Middle Yangtze River basin.

Author Contributions: Conceptualization, T.W.; methodology, T.W. and Y.W.; software, Y.W.; validation, T.W. and J.H.; formal analysis, Y.W. and P.T.; investigation, T.W. and Y.W.; resources, J.H. and H.Z.; data curation, T.W. and Y.W.; writing-original draft preparation, T.W. and Y.W.; writing-review and editing, J.H., T.Y. and P.T.; visualization, Y.W.; supervision, T.W. and J.H.; project administration, T.W.; funding acquisition, T.W. All authors have read and agreed to the published version of the manuscript.

Funding: This research was funded by the National Natural Science Foundation of China, grant number 41701323, 41907061, and 41771261, and State Scholarship Fund of China, grant number 201806775033. This study was also partially supported by research funds of Central China Normal University from the college's basic research and Ministry of Education, grant number CCNU20QN033.

Acknowledgments: The authors thank Pin Ma, Xingwen Fan, and Yuanyong Luo for their help in field works. 
Conflicts of Interest: The authors declare no conflict of interest.

\section{References}

1. Yang, W.; Li, Z.; Cai, C.; Guo, Z.; Chen, J.; Wang, J. Mechanical properties and soil stability affected by fertilizer treatments for an Ultisol in subtropical China. Plant Soil 2013, 363, 157-174. [CrossRef]

2. Barthès, B.G.; Kouakoua, E.; Larré-Larrouy, M.; Razafimbelo, T.M.; de Luca, E.F.; Azontonde, A.; Neves, C.S.V.J.; de Freitas, P.L.; Feller, C.L. Texture and sesquioxide effects on water-stable aggregates and organic matter in some tropical soils. Geoderma 2008, 143, 14-25. [CrossRef]

3. Erguler, Z.A.; Ulusay, R. Assessment of physical disintegration characteristics of clay-bearing rocks: Disintegration index test and a new durability classification chart. Eng. Geol. 2009, 105, 11-19. [CrossRef]

4. Wu, Y.; Chen, J. Modeling of soil erosion and sediment transport in the East River Basin in southern China. Sci. Total Environ. 2012, 441, 159-168. [CrossRef] [PubMed]

5. Shi, X.Z.; Yu, D.S.; Warner, E.D.; Sun, W.X.; Petersen, G.W.; Gong, Z.T.; Lin, H. Cross-Reference System for Translating Between Genetic Soil Classification of China and Soil Taxonomy. Soil Sci. Soc. Am. J. 2006, 70, 78-83. [CrossRef]

6. Hu, X.; Jiang, W.; Ye, W.; Shen, M.; Zhang, W.; Wang, H.; Lu, C.; Zhu, L. Yellow-brown earth on Quaternary red clay in Langxi County, Anhui Province in subtropical China: Evidence for paleoclimatic change in late Quaternary period. J. Plant Nutr. Soil Sci. 2008, 171, 542-551. [CrossRef]

7. Zhang, M.K.; Xu, J.M. Restoration of surface soil fertility of an eroded red soil in southern China. Soil Till. Res. 2005, 80, 13-21. [CrossRef]

8. Yin, Q.; Guo, Z. Mid-Pleistocene vermiculated red soils in southern China as an indication of unusually strengthened East Asian monsoon. Chin. Sci. Bull. 2006, 51, 213-220. [CrossRef]

9. Eze, P.N.; Udeigwe, T.K.; Meadows, M.E. Plinthite and Its Associated Evolutionary Forms in Soils and Landscapes: A Review. Pedosphere 2014, 24, 153-166. [CrossRef]

10. Hong, H.; Gu, Y.; Yin, K.; Zhang, K.; Li, Z. Red soils with white net-like veins and their climate significance in south China. Geoderma 2010, 160, 197-207. [CrossRef]

11. Liu, C.; Deng, C.; Liu, Q. Mineral magnetic studies of the vermiculated red soils in southeast China and their paleoclimatic significance. Palaeogeogr. Palaeocl. 2012, 329, 173-183. [CrossRef]

12. Hu, X.; Cheng, T.; Wu, H. Do multiple cycles of aeolian deposit-pedogenesis exist in the reticulate red clay sections in southern China. Chin. Sci. Bull. 2003, 48, 1251-1258. [CrossRef]

13. Hu, X.; Zhu, Y.; Shen, M. Grain-size evidence for multiple origins of the reticulate red clay in southern China. Chin. Sci. Bull. 2005, 50, 910-918. [CrossRef]

14. Fritsch, E.; Herbillon, A.J.; Do Nascimento, N.R.; Grimaldi, M.; Melfi, A.J. From Plinthic Acrisols to Plinthosols and Gleysols: Iron and groundwater dynamics in the tertiary sediments of the upper Amazon basin. Eur. J. Soil Sci. 2007, 58, 989-1006. [CrossRef]

15. Liu, C.; Deng, C. The effect of weathering on the grain-size distribution of red soils in south-eastern China and its climatic implications. J. Asian Earth Sci. 2014, 94, 94-104. [CrossRef]

16. Hu, X.; Du, Y.; Liu, X.; Zhang, G.; Jiang, Y.; Xue, Y. Polypedogenic case of loess overlying red clay as a response to the Last Glacial-Interglacial cycle in mid-subtropical Southeast China. Aeolian Res. 2015, 16, 125-142. [CrossRef]

17. Xie, S.; Lai, X.; Yi, Y.; Gu, Y.; Liu, Y.; Wang, X.; Liu, G.; Liang, B. Molecular fossils in a Pleistocene river terrace in southern China related to paleoclimate variation. Org. Geochem. 2003, 34, 789-797. [CrossRef]

18. Arriaga, F.J.; Lowery, B. Corn production on an eroded soil: Effects of total rainfall and soil water storage. Soil Till. Res. 2003, 71, 87-93. [CrossRef]

19. Bryan, R.B. Soil erodibility and processes of water erosion on hillslope. Geomorphology 2000, 32, $385-415$. [CrossRef]

20. Batista, P.V.G.; Davies, J.; Silva, M.L.N.; Quinton, J.N. On the evaluation of soil erosion models: Are we doing enough? Earth Sci. Rev. 2019, 197, 102898. [CrossRef]

21. Cosby, B.J.; Hornberger, G.M.; Clapp, R.B.; Ginn, T.R. A Statistical Exploration of the Relationships of Soil Moisture Characteristics to the Physical Properties of Soils. Water Resour. Res. 1984, 20, 682-690. [CrossRef] 
22. Hao, Y.; Liu, Q.; Li, C.; Kharel, G.; An, L.; Stebler, E.; Zhong, Y.; Zou, C.B. Interactive Effect of Meteorological Drought and Vegetation Types on Root Zone Soil Moisture and Runoff in Rangeland Watersheds. Water 2019, 11, 2357. [CrossRef]

23. Andruschkewitsch, R.; Koch, H.; Ludwig, B. Effect of long-term tillage treatments on the temporal dynamics of water-stable aggregates and on macro-aggregate turnover at three German sites. Geoderma 2014, 217, 57-64. [CrossRef]

24. Leung, A.K.; Garg, A.; Ng, C.W.W. Effects of plant roots on soil-water retention and induced suction in vegetated soil. Eng. Geol. 2015, 193, 183-197. [CrossRef]

25. Wang, M.; Xu, P.; Li, J.; Qin, S. Microstructure and Unsaturated Geotechnical Properties of Net-like Red Soils in Xuancheng, China. J. Test. Eval. 2015, 43, 1-13. [CrossRef]

26. Wildemeersch, J.C.J.; Garba, M.; Sabiou, M.; Sleutel, S.; Cornelis, W. The Effect of Water and Soil Conservation (WSC) on the Soil Chemical, Biological, and Physical Quality of a Plinthosol in Niger. Land Degrad. Dev. 2015, 26, 773-783. [CrossRef]

27. Haruna, S.I.; Anderson, S.H.; Nkongolo, N.V.; Zaibon, S. Soil Hydraulic Properties: Influence of Tillage and Cover Crops. Pedosphere 2018, 28, 430-442. [CrossRef]

28. Çerçioğlu, M.; Anderson, S.H.; Udawatta, R.P.; Alagele, S. Effect of cover crop management on soil hydraulic properties. Geoderma 2019, 343, 247-253. [CrossRef]

29. Fu, Q.; Zhao, H.; Li, T.; Hou, R.; Liu, D.; Ji, Y.; Zhou, Z.; Yang, L. Effects of biochar addition on soil hydraulic properties before and after freezing-thawing. Catena 2019, 176, 112-124. [CrossRef]

30. Chang, C.; Cheng, D.; Qiao, X. Improving estimation of pore size distribution to predict the soil water retention curve from its particle size distribution. Geoderma 2019, 340, 206-212. [CrossRef]

31. Lin, L.; Chen, J. The effect of conservation practices in sloped croplands on soil hydraulic properties and root-zone moisture dynamics. Hydrol. Process. 2015, 29, 2079-2088. [CrossRef]

32. Soil Survey Staff. Keys to Soil Taxonomy, 11th ed.; USDA-NRCS, U.S. Government Printing Office: Washington, DC, USA, 2010; p. 329.

33. Bagarello, V.; Baiamonte, G.; Caia, C. Variability of near-surface saturated hydraulic conductivity for the clay soils of a small Sicilian basin. Geoderma 2019, 340, 133-145. [CrossRef]

34. Tian, Z.; Kool, D.; Ren, T.; Horton, R.; Heitman, J.L. Approaches for estimating unsaturated soil hydraulic conductivities at various bulk densities with the extended Mualem-van Genuchten model. J. Hydrol. 2019, 572, 719-731. [CrossRef]

35. Yoder, R.E. A Direct Method of Aggregate Analysis of Soils and a Study of the Physical Nature of Erosion Losses. Agron. J. 1936, 28, 165-169. [CrossRef]

36. Pinheiro, E.F.M.; Pereira, M.G.; Anjos, L.H.C. Aggregate distribution and soil organic matter under different tillage systems for vegetable crops in a Red Latosol from Brazil. Soil Till. Res. 2004, 77, 79-84. [CrossRef]

37. Ahmadi, A.; Neyshabouri, M.R.; Rouhipour, H.; Asadi, H. Fractal dimension of soil aggregates as an index of soil erodibility. J. Hydrol. 2011, 400, 305-311. [CrossRef]

38. Tagar, A.A.; Adamowski, J.; Memon, M.S.; Do, M.C.; Mashori, A.S.; Soomro, A.S.; Bhayo, W.A. Soil fragmentation and aggregate stability as affected by conventional tillage implements and relations with fractal dimensions. Soil Till. Res. 2020, 197, 104494. [CrossRef]

39. Grossman, R.B.; Reinsch, T.G. Bulk Density and Linear Extensibility. In Methods of Soil Analysis: Physical Methods; Dane, J.H., Topp, G.C., Eds.; Part 4; Soil Science Society of America: Madison, WI, USA, 2002; pp. 201-228.

40. Van Genuchten, M.; Leij, F.J.; Yates, S.R. The RETC Code for Quantifying the Hydraulic Functions of Unsaturated Soils, Version 1.0; U.S. Salinity Laboratory: Riverside, CA, USA, 1991; pp. 4-32.

41. Ghanbarian-Alavijeh, B.; Liaghat, A.; Huang, G.; van Genuchten, M. Estimation of the van Genuchten Soil Water Retention Properties from Soil Textural Data. Pedosphere 2010, 20, 456-465. [CrossRef]

42. Sahu, B.K. Depositional mechanism from the size analysis of sediments. J. Sediment. Res. 1964, 34, 73-83.

43. Yang, S.; Li, C.; Zhang, J. Palaeogeographic Evolution Coastal Plain and Provence Study of Postglacial Sediments in North Jiangsu. J. Palaeogeog-English. 2000, 2, 68-75.

44. Li, C.; Wang, Y. Preliminary exploration on grain characteristic and discrimination of debris flow deposit, moraine and river \& like deposit. Mt. Res. 1999, 17, 51-55, (In Chinese with English Abstract). 
45. Zhang, P.; Song, C.; Yang, Y.; Gao, H.; Zhang, H.; Liu, W.; Pan, M.; Liu, P.; Hu, S.; Xia, W. The significance and establishment of discriminant function with grain size of stable lacustrine sediment and aeolian loess. Acta Sedimentol. Sinca 2008, 26, 501-507.

46. Lu, H.; Vandenberghe, J.; An, Z. Aeolian origin and palaeoclimatic implications of the 'Red Clay' (north China) as evidenced by grain-size distribution. J. Quat. Sci. 2001, 16, 89-97. [CrossRef]

47. Le Bissonnais, Y. Aggregate stability and measurement of soil crustability and erodibility: I. Theory and methodology. Eur. J. Soil Sci. 1996, 47, 425-437. [CrossRef]

48. Babu, S.; Peter, J.; Mukesh, M.D.; Gartung, E. Significance of soil suction and soil water characteristic curve parameters. Geo-tech. Test. J. 2005, 28, 102-107.

49. Zhang, Z.; Pendin, V.; Nikolaeva, S.; Zhang, Z.; Wu, J. Disintegration characteristics of a cryolithogenic clay loam with different water content: Moscow covering loam ( $\left.p r \mathrm{Q}_{\mathrm{III}}\right)$, case study. Eng. Geol. 2019, 258, 105159.

50. Jabro, J.D. Estimation of Saturated Hydraulic Conductivity of Soils from Particle Size Distribution and Bulk Density Data. Trans. ASABE. 1992, 35, 557-560. [CrossRef]

51. Réfloch, A.; Gaudet, J.; Oxarago, L.; Rossier, Y. Estimation of saturated hydraulic conductivity from ring infiltrometer test taking into account the surface moisture stain extension. J. Hydrol. Hydromech. 2017, 65, 321-324. [CrossRef]

52. Mirko, C.; Anna Maria, S.; Matteo, T.; Emanuele, B. Spatial Variability of Soil Physical and Hydraulic Properties in a Durum Wheat Field: An Assessment by the BEST-Procedure. Water 2019, 11, 1434.

53. Feng, L.; Lin, H.; Zhang, M.; Guo, L.; Jin, Z.; Liu, X. Development and evolution of Loess vertical joints on the Chinese Loess Plateau at different spatiotemporal scales. Eng. Geol. 2020, 265, 105372. [CrossRef]

54. Wang, J.D.; Gu, T.F.; Zhang, M.S.; Xu, Y.J.; Kong, J.X. Experimental study of loess dis-integration characteristics. Earth Surf. Proc. Land. 2019, 44,1317-1329. [CrossRef]

55. Zhang, J.; Gu, P.; Li, L.; Zhao, W. Changes of soil particle size fraction along a chronosequence in sandy desertified land: A fundamental process for ecosystem succession and ecological restoration. J. Soils Sediments 2016, 16, 2651-2656. [CrossRef]

56. Chen, Y.; Li, X.; Han, Z.; Yang, S.; Wang, Y.; Yang, D. Chemical Weathering Intensity and Element Migration Features of the Xiashu Loess Profile in Zhenjiang. J. Geogr. Sci. 2008, 18, 341. [CrossRef]

57. Barthes, B.; Roose, E. Aggregate stability as an indicator of soil susceptibility to runoff and erosion; validation at several levels. Catena 2002, 47, 133-149. [CrossRef]

58. Wu, X.; Wei, Y.; Wang, D.; Wang, J.; Wang, J.; She, L.; Cai, C. Effects of soil physicochemical properties on aggregate stability along a weathering gradient. Catena 2017, 156, 205-215. [CrossRef]

59. Zhang, Z.; Liu, W.; Han, L.; Chen, X.; Cui, Q.; Yao, H.; Wang, Z. Disintegration behavior of strongly weathered purple mudstone in drawdown area of three gorges reservoir, China. Geomorphology 2018, 315, 68-79. [CrossRef]

60. Andrade, G.R.P.; Azevedo, A.C.; Lepchak, J.K.; Assis, T.C. Weathering of Permian sedimentary rocks and soil clay minerals transformations under subtropical climate, southern Brazil (Paraná State). Geoderma 2019, 336, 31-48. [CrossRef]

61. Hunt, A.G.; Ghanbarian, B. Percolation theory for solute transport in porous media: Geochemistry, geomorphology, and carbon cycling. Water Resour. Res. 2016, 52, 7444-7459. [CrossRef]

62. Wu, T.N.; Lin, H.; Zhang, H.L.; Ye, F.; Wang, Y.W.; Liu, M.X.; Yi, J.; Tian, P. Effects of climatic change on soil hydraulic properties during the last interglacial: Two case studies on the Southern Chinese Loess Plateau. Water 2020, 12, 511. [CrossRef]

(C) 2020 by the authors. Licensee MDPI, Basel, Switzerland. This article is an open access article distributed under the terms and conditions of the Creative Commons Attribution (CC BY) license (http://creativecommons.org/licenses/by/4.0/). 